\title{
Barsauma von Nisibis und die Aufhebung der Klerikerenthaltsamkeit im Gefolge der Synode von Beth-Lapat (484)*
}

\author{
PETER BRUNS / BAMBERG
}

Als der flämische Franziskaner Wilhelm von Rubruk ${ }^{1}$ in den Jahren 1253-1255 im Auftrag des französischen Königs eine Gesandtschaft in die Mongolei begleitete, stellte er zu seinem Erstaunen fest, daß in der Nähe des Balkaschsees ganze Dörfer christlich waren und die Liturgie dort in der angestammten syrischen Kirchensprache zelebriert wurde. Auch bei den Uiguren im nördlichen China war das Christentum in seiner nestorianischen Variante stark verbreitet. Über die nestorianischen Priester schreibt Wilhelm, daß sie ihre Weihe als junge Männer empfingen und dennoch später heiraten würden, was doch contra statuta patrum sei. Doch damit nicht genug; Wilhelm fährt fort: Sie heiraten sogar nach dem Ableben der ersten Frau ein zweites Mal, weil selbst die Priester nach dem Tode der ersten Frau eine andere nebmen. Wilhelm wußte als Europäer nicht viel über das orientalische, speziell nestorianische Christentum. Die Zweitehe (bigamismus) und die Klerikerehe der Nestorianer waren dem Franziskaner unbekannt, ja suspekt. Was er als contra statuta patrum brandmarkt, war freilich in der "Kirche des Ostens" seit den Tagen des Barșaumâ² (gräzisiert Bars[a]umas, der Fastensobn), seit der zweiten Hälfte des fünften Jahrhunderts also, die gängige Rechtspraxis geworden.

* Erheblich erweiterte Fassung eines Vortrags, gehalten auf der Tagung für Konziliengeschichte in Rom (16.-20.9.2004).

${ }^{1}$ Lat. Ausgabe der Reiseberichte mit ausführlicher Kommentierung bei A. VAN DEN WYNGAERT, Sinica Franciscana I. Itinera et relationes fratrum minorum saeculi XIII et XIV, Quaracchi-Firenze 1929; die Beschreibung der nestorianischen Kleriker findet sich in Itinerarium 26,12-14 (WYNGAERT 238).

${ }^{2}$ Das Standardwerk zu Barsauma ist noch immer ST. GERÖ, Barsauma and Persian Christianity, Louvain 1981; zum Namen Fastensobn, der nicht unbedingt auf einen asketischen Hintergrund verweist, 25, Anm. 4. Keine neueren Einsichten bietet der Beitrag von B. SCHMITZ, Barsauma von Nisibis († 495), in: W. KLEIN (Hg.), Syrische Kirchenväter, Stuttgart 2004, 102-110.

AHC 37 (2005) 


\section{Leben und Wirken des Barsauma von Nisibis}

Barsaumas Leben bietet genügend Stoff für gleich mehrere Romane. Der Bischof von Nisibis gehört zu den schillerndsten Gestalten, die das persische Christentum im fünften Jahrhundert hervorgebracht hat. Für die Rekonstruktion seiner Vita kommen verschiedene Quellen ${ }^{3}$ in Betracht; die homiletischen und liturgischen Werke aus seiner Feder tragen hierzu viel weniger bei als die im Synodicon Orientale ${ }^{4}$ überlieferten Briefe. Ergiebiger in diesem Punkt sind freilich die über die Chroniken unterschiedlicher Provenienz $z^{5}$ verstreuten Nachrichten. Barsauma stammte demnach aus einfachen Verhältnissen; nach dem Zeugnis des monophysitischen Autors Simeon von Beth-Arschâm ${ }^{6}$ soll er der Sklave eines kurdischen Herren gewesen sein. Die Herkunft aus der Provinz Beth Qardu (Kurdistan) nordöstlich von Nisibis, dem Gebirgszug östlich des Tigris, ist in der Forschung unbestritten. Keine Handhabe hingegen besitzen wir für die exakte Bestimmung des Geburtsalters Barsaumas; die Forscher schwanken hier zwischen 400 und $420^{7}$. Barsaumas Muttersprache war zwei-

${ }^{3} \mathrm{Zu}$ den Quellen allgemein vgl. GeRÖ, Barsauma (wie Anm. 2), 1-13; zur Vita im besonderen 25-59.

${ }^{4}$ Syr. Text bei J. B. ChabOt, Synodicon Orientale ou Recueil de Synodes nestoriens, Paris 1902. Chabots Edition basiert auf zwei Manuskripten (Borg. 82) und Par. syr. 332; die dt. Übersetzung bei O. BRAUN, Das Buch der Synhados oder Synodicon Orientale, StuttgartWien 1900, (repr. Amsterdam 1975), wurde lediglich nach der römischen Handschrift angefertigt.

${ }^{5}$ Ein Grundproblem in der Darstellung bei Gerö besteht darin, daß er den monophysitischen Quellen jeglichen historischen Wert abspricht. Gewiß hat die monophysitische Propaganda manches im Leben des Barsauma übertrieben, doch ist auch die nestorianische Geschichtsschreibung keineswegs gegen Einseitigkeiten gefeit. Im Gegenteil, den monophysitischen Quellen ist oft mehr zu trauen, zumal da sogar die nestorianischen Apologeten unseren Autor in vielen Anklagepunkten schwer belasten. Angesichts des oft recht disparaten Quellenbefundes hat sich der Historiker also sein eigenes, kritisches Urteil zu bilden.

${ }^{6} \mathrm{~J}$. S. Assemanus, Bibliotheca Orientalis Clementino-Vaticana I-III, Romae 1719-1728 (repr. Hildesheim 2000), I, 346-358, hier 351f: wa-Barșaumâ 'abdâ d-mârâ qardâwyâ. Man kann syr. mârâ auch als Eigennamen auffassen: ein Sklave des Mara aus dem Kurdenland (so bei Assemani). GERÖ, Barsauma (wie Anm. 2), 27, Anm. 8, hält diese Information für reine Polemik, die er aus der literarischen Topik ihrer Zeit erklärt. Daß Barsauma später mit den hohen persischen Beamten auf gutem Fuß stand, spricht eher für eine Abkunft von Freien; zu Leben und Werk des Barsauma vgl. auch ASSEMANI, BOCV III/1,66-70.

${ }^{7}$ Gerö ist ein vehementer Verfechter der Frühdatierung, vgl. GERÖ, Barsauma (wie Anm. 2), 33, Barsauma wäre dann bei seinem Tode 495 weit über neunzig gewesen. Für ein mittleres Alter votiert J. LABOURT, Le christianisme dans l'empire perse sous la dynastie sassanide (224-632), Paris 1904, 131. 
felsohne Syrisch, doch sprach er auch vorzüglich Pahlavi, wie seine Kontakte zur persischen Obrigkeit belegen; Griechisch hat er schließlich in Edessa gelernt und durch stete Verhandlungen mit den Byzantinern perfektioniert. Es war gerade das Studium in Edessa an der sog. "Perserschu-

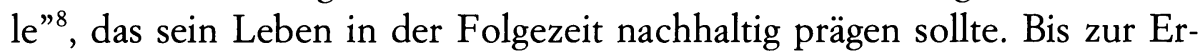
richtung der Schule von Nisibis ${ }^{9}$ war Edessa das theologische Zentrum für das nördliche Zweistromland. Nach Auskunft des nestorianischen Chronisten Barhadbeschabba ${ }^{10}$ war Barsauma ein außergewöhnlich begabter junger Mann mit einer schnellen Auffassungsgabe, die es ihm ermöglichte, die Studien rasch und erfolgreich zu beenden. Schwerpunkt bildete die historisch-grammatische Exegese auf der dogmatischen Basis einer streng antiochenischen Christologie. Der Monophysit Simeon von Beth-Arscham teilt uns noch den studentischen Spitznamen des Barsauma mit: Nestscbwimmer ${ }^{11}$, eine Bezeichnung, die unterschiedliche Deutungen offenläßt. Es ist nicht ausgeschlossen, daß Barsauma nach seinen Studien selber in Edessa gelehrt hat, Leiter der dortigen Schule wie sein Studienfreund Narsai (auch Narse, gräzisiert Narses) war er jedoch wohl nicht. Möglicherweise gehörte er zu jenem Übersetzerteam, das unter der Schirmherrschaft des Bischofs Hibâ (gräzisiert Ibas, † 457) die Werke Theodors von Mopsuestia aus dem Griechischen ins Syrische übertrug. Die Situation in Edessa eskalierte, als die Anhänger des 435 verstorbenen Bischofs Rabbula versuchten, den neuen Bischof Ibas abzusetzen, was ihnen 449 auf der sog. "Räubersynode" schließlich auch gelang. Damals verlangten die Kleriker und Archimandriten in einer Bittschrift ( $\psi \eta \dot{\varphi} \varphi \iota$ -

\footnotetext{
${ }^{8}$ Vgl. dazu P. BRunS, Die sog. "Perserschule" von Edessa und ihr Einfluß auf die Synoden im Zweistromland, in: AHC 35 (2003) 345-364. Das Standardwerk zur Perserschule ist noch immer E. R. HAYES, L'école d'Édesse, Paris 1930. Ein Gesamtüberblick über die Schulen des Zweistromlandes findet sich bei H. R. NELZ, Die theologischen Schulen der morgenländischen Kirchen während der sieben ersten christlichen Jahrhunderte in ihrer Bedeutung für die Ausbildung des Klerus, Bonn 1916.

${ }^{9}$ Vgl. dazu A. VÖÖBUS, History of the School of Nisibis, Louvain 1965 (= CSCO 266), bes. 7-56 (der Einfluß Edessas auf die neue Schule).

${ }^{10}$ PO IX/5,597,12-14: Da Barsauma ein scharfsinniger Mann war, lernte er schnell dazu und wurde ein Glanzlicht in den Schriften und ibres Bedeutungssinnes, mebr als alle übrigen.

${ }^{11}$ Vielleicht in der Bedeutung von Trockenschwimmer, der das tiefe Wasser scheut. Verschiedene Deutungen bei GERÖ, Barsauma (wie Anm. 2), 28, Anm. 14. Doch kommt er ohne Konjekturen (Robrschwimmer, Rohrpisser) nicht aus.
} 
$\mu \alpha)^{12}$ nicht nur die Absetzung des häretischen, weil nestorianisch gesinnten Bischofs Ibas, sondern auch die Exilierung der Perser Babai, Barsauma (sic!) und Balasch (Vologeses). Für die strengen "Theodorianer" wurde das Pflaster in Edessa zu heiß, auch wenn durch die Rehabilitierung des Ibas in Chalkedon 451 wieder eine kurze Phase der Entspannung eintreten sollte. Mit dem Tode des Bischofs 457 fehlte der streng antiochenischen Perserschule von Edessa die kirchenpolitische Stütze. Spätestens zu diesem Zeitpunkt dürfte der große Exodus der Perser nach Nisibis ${ }^{13}$ begonnen haben. Unklar ist, wann Barsauma endgültig in die von den Persern besetzte Nachbarmetropole übergesiedelt ist. Dort versah er an der Bischofskirche sehr zum Entzücken von Klerus und Volk das Predigeramt ( $m^{e}$ targmânâ). Nach dem Ableben des Ortsbischofs wurde er einmütig zum Nachfolger ${ }^{14}$ akklamiert. Gerö datiert Barsaumas Bischofsweihe auf das Jahr 435 (746 Sel. $)^{15}$; doch erscheint dies nach allem, was wir wissen, ziemlich früh. Eine Manuskripttradition zu Elias von Nisibis ${ }^{16}$ nennt das Jahr Sel. 757 (A.D. 446), andere wiederum nehmen eine Koinzidenz mit dem Regierungsantritt des Großkönigs Peroz (459-484) an. M. J. Fiey ${ }^{17}$ votiert daher für die Zeit unmittelbar nach dem Ableben des

${ }^{12}$ J. FLEMING, Akten der Ephesinischen Synode vom Jahre 449. Syrisch mit Georg Hoffmanns deutscher Übersetzung und seinen Anmerkungen, Berlin 1917 (= AGWG.PH 15), (repr. Göttingen 1970), 26,28f (Übers. 27,40f). Vgl. auch Hoffmanns Bemerkungen 171, der den hier genannten Barsauma gleichfalls mit dem späteren Bischof von Nisibis identifiziert. Doch angesichts der großen Verbreitung des Namens ist in diesem Punkt gewisse Vorsicht angebracht.

${ }^{13}$ Dies ist die Ansicht der meisten Chronisten wie Simeon von Beth-Arscham, aber auch der nestorianischen Chronik von Arbela, vgl. P. KAWERAU, Die Chronik von Arbela (CSCO 468), Louvain 1985, $96 f$ (syr. in CSCO 467,70f), die Bedenken bei GERÖ, Barsauma (wie Anm. 2), $30 \mathrm{f}$.

${ }^{14}$ So in der Kirchengeschichte des Barhadbeschabba (PO IX/5, 598). Auch NAU, ebd., Anm. 1, versieht das Datum 435 mit einem Fragezeichen.

${ }^{15}$ Vgl. dazu GerÖ, Barsauma (wie Anm. 2), 32f. Selbst wenn man mit Gerö das Geburtsjahr um 400-405 ansetzt, wäre Barsauma bereits in sehr jungen Jahren zum Bischof geweiht geworden. Man sollte in diesem Zusammenhang bedenken, daß das Weihealter für den Bischof in der syrischen Didaskalie 2,1-3 (Funk 30-35) beim fünfzigsten Lebensjahr lag, nur in Ausnahmefällen konnte von dieser Regelung abgewichen werden. Hinzukommt, daß, wie Gerö eingestehen muß, mittelalterliche Bischofslisten von Nisibis nach dem Tode des Hoseas $(† 424)$ und dem Episkopat des Barsauma drei bis fünf Namen einfügen.

${ }^{16}$ Vgl. hierzu die Diskussion bei GERÖ, Barsauma (wie Anm. 2), 32, Anm. 36.

${ }^{17}$ Vgl. dazu M. J. FIEY, Jalons pour une histoire de l'église en Iraq, Louvain 1970 (= CSCO 310), 113, Anm. 3 . 
Ibas von Edessa (457). Der Nestorianer Barhadbeschabba ${ }^{18}$ hingegen erweckt in seiner Geschichte der Schulen den Eindruck, daß die Bischofsweihe des Barsauma mit der Erhebung des Narsai zum Rektor der Schule von Edessa zusammenfällt, was gleichfalls für die Frühdatierung in die dreißiger Jahre spräche. Die Unklarheiten in der Chronologie ${ }^{19}$ bleiben also weiter bestehen.

Das Leben eines orientalischen Bischofs in der Spätantike hatte durchaus seine angenehmen Seiten, wie das Beispiel des Paul von Samosata ${ }^{20}$, des Kämmerers der palmyrenischen Königin Zenobia, zeigt. Barsauma machte hiervon keine Ausnahme. Als Bischof von Nisibis war er vornehmlich Politiker ${ }^{21}$; von einer überragenden caritativen Tätigkeit sprechen die Quellen nirgends, noch weniger von einer strengen Aszese, wie sie gerade im syrischen Raum ${ }^{22}$ üblich war. Barsauma war ein blendender Organisator, der während seiner Regentschaft das akademische Leben der Stadt Nisibis zusammen mit seinem Studienfreund Narsai ${ }^{23}$ neu regelte. Gegen Oppositionelle in der Diözese ${ }^{24}$ griff der Bischof hart durch. Die

${ }^{18}$ Vgl. PO IV/4,383f. Doch sind die Ausführungen des Nestorianers zum Thema nicht weniger schematisch als die von GERÖ, Barsauma (wie Anm. 2), 32, oft beklagte "künstliche Synchronisation" der Monophysiten. In der Kirchengeschichte des gleichnamigen Autors ist lediglich vom Empfang des Hohenpriestertums ohne Zeitangabe die Rede: qabbel chiritoniâ drabbût kûmrûtâ.

${ }^{19}$ Man könnte eine gewisse Harmonisierung der divergierenden Angaben innerhalb der nestorianischen Tradition dadurch versuchen, indem man die Priesterweihe auf 435 datiert und die Bischofsweihe für die späten Regierungsjahre des Ibas verschiebt. GERÖ, Barsauma (wie Anm. 2), 32, Anm. 32, vermutet wohl nicht zu Unrecht, daß Ibas schon in jungen Jahren Barsauma im Hinblick auf eine spätere Karriere als Bischof protegierte.

${ }^{20}$ Vgl. dazu J. RIST, Cyprian von Karthago und Paul von Samosata. Überlegungen zum Verständnis des Bischofsamtes im 3. Jahrhundert, in: R. v. HAEHLING, Rom und das himmlische Jerusalem, Darmstadt 2000, 257-286.

${ }^{21}$ Vgl. hierzu die Charakterisierung bei GERÖ, Barsauma (wie Anm. 2), 95: "Though a trained theologian and exegete, Barșauma was not a speculative thinker but rather a realistic politician and a man of action, in an ecclesiastical context to be sure".

${ }^{22}$ Es wäre gewiß lohnend, das Leben des Barsauma mit dem des großen Widersachers der Perserschule von Edessa, des Bischofs Rabbula, zu vergleichen, vgl. dazu G. G. BLUM, Rabbula von Edessa. Der Christ, der Bischof, der Theologe, Louvain 1969 (= CSCO 300).

${ }^{23}$ Barsauma kaufte kurzerhand eine leerstehende Karawanserei und baute sie zur Schule um, vgl. VÖÖBUS, History (wie Anm. 9), 47-56; GERÖ, Barsauma (wie Anm. 2), 60-72.

${ }^{24}$ Die Opposition war sowohl religiös als auch politisch motiviert. Manche in der Diözese hielten insgeheim mit den Römern, andere waren mit Barsaumas kirchenpolitischem Kurs unzufrieden und vertraten eine andere Lehrmeinung in der Christologie. Insgesamt dürfte das monophysitische wie auch chalkedonische (melkitische) Bekenntnis den Persern "römischer" als das nestorianische erschienen sein. Besonders schmerzlich mußte es für Barsauma gewesen 
Finanzen hielt er in Ordnung, Klagen über schlechte Buchführung oder gar Unterschlagung wie beim Edessener Bischof $\mathrm{Ibas}^{25}$ suchen wir bei Barsauma vergebens. Im Gegenteil, Barsaumas Schatulle war stets gut gefüllt, so daß er sich mit größeren Beträgen die Mitbrüder $^{26}$ gefügig zu machen wußte. Für literarisches Schaffen blieb da freilich wenig Raum, und anders als bei dem Studienfreund Narsai ist vom literarischen Nachlaß (Homilien, Reden und Gebete $)^{27}$ so gut wie nichts erhalten geblieben. Barsaumas umfangreiche Korrespondenz ${ }^{28}$ zeigt ihn eher als versierten Diplomaten und karrierebewußten Politiker. Als solcher ist er der Nachwelt in Erinnerung geblieben und als solchen haben ihn die damaligen Zeitgenossen durchaus geschätzt oder gefürchtet. Intensive Kontakte pflegte Barsauma zum persischen Standortkommandanten von Nisibis, dem Marzpan (Markgrafen) Qardag (oder Bardag) Nakoragan, der sich zu Friedensverhandlungen mit dem byzantinischen $d u x$ der Vermittlung des Ortsbischofs $^{29}$ bediente. Seit den Tagen des Marutha von Maipherkat (410) zogen die persischen und byzantinischen Behörden bei heiklen Missionen die Bischöfe des Grenzlandes ${ }^{30}$ hinzu. Bisweilen fungierten diese auch als "informelle Mitarbeiter" der jeweiligen Regierungen. So informierte Bar-

sein, daß der Marzpan sogar den "Rebellen" die versöhnende Hand reichte, vgl. CHABOT, Synodicon Orientale (wie Anm. 4.), 528f. 535.

${ }^{25}$ Einer der Hauptanklagepunkte bei der sog. "Räubersynode" von Ephesus (449) neben dem Häresievorwurf lautet auf Veruntreuung kirchlicher Güter, vgl. FLEMING, Akten (wie Anm. 12), 23.

${ }^{26}$ Signifikant ist die Art, mit der sich Barsauma auch beim neuen Katholikos Aqâq beliebt zu machen suchte, indem er ihm einmalig hundert Golddareiken überwies und jedes Jahr fünfzig weitere versprach, vgl. СНАВОT, Synodicon Orientale (wie Anm. 4.), 530 . Auch wenn der Münzwert umstritten ist, handelt es sich keineswegs um einen kleineren Betrag, vgl. GERÖ, Barsauma (wie Anm. 2), 34, Anm. 43, zumal da Goldmünzen in der Sasanidenzeit seltener waren, vgl. dazu K. SCHIPPMANN, Grundzüge der Geschichte des Sasanidischen Reiches, Darmstadt 1990, 138f. Schippmanns überblickartige Darstellung kann das Standardwerk von A. CHRISTENSEN, L'Iran sous les Sassanides, Kopenhagen, ${ }^{2} 1944$, keineswegs ersetzen.

${ }^{27}$ Vgl. dazu A. BAUMSTARK, Geschichte der syrischen Literatur, Bonn 1922, (repr. Berlin 1968), 108f; vgl. den Schriftstellerkatalog des Ebedjesu, zitiert bei AsSEMANI, BOCV (wie Anm. 6) III,66.

${ }^{28}$ Zur Chronologie der Briefe vgl. GeRÖ, Barsauma (wie Anm. 2), 89-93; die Briefe wurden von СНАВОт, Synodicon Orientale (wie Anm. 4), 525-539, ediert.

${ }^{29}$ Vgl. ep. 2, ebd., 527. 533. Der $d u x$ war ein niederer General, der neben regulären Truppen auch die arabischen Hilfstruppen, vor allem Reiter, kommandierte.

${ }^{30} \mathrm{Vgl}$. dazu L. SAKO, Le rôle de la hiérarchie syriaque-orientale dans les rapports diplomatiques entre la Perse et Byzance aux V V $-\mathrm{VII}^{\mathrm{e}}$ siècles, Paris 1986. 
sauma etwa den Marzpan (Markgrafen) über Truppenbewegungen arabischer Nomaden ${ }^{31}$ an der persischen Grenze. Nestorianische Quellen heben Barsaumas uneingeschränkte Loyalität gegenüber dem Großkönig Peroz hervor, monophysitische Chronisten machen ihn gar zu seiner rechten Hand. Eine solche Anklage erscheint um so bemerkenswerter, als dieser Herrscher nämlich für seinen $\mathrm{Haß}$ auf die christliche Religion ${ }^{32}$ bekannt geworden ist. Peroz war nach einem längeren Thronstreit mit dem Bruder Hormizd III. (457-459) ${ }^{33}$ nur dank der Hilfe seiner hunnischen Vasallen, der Hephthaliten, an die Macht gekommen. Dürre und ständige Reibereien an der Ostfront überschatteten seine Regentschaft ${ }^{34}$. Bei einem unglücklichen Feldzug im Osten geriet der Großkönig mit seinem Sohn in Gefangenschaft und konnte sich nur gegen hohes Lösegeld freikaufen. Die christlichen Armenier und Georgier, die erst kürzlich dem Perserreich gewaltsam einverleibt worden waren, nutzten die Gunst der Stunde zu einem großen Volksaufstand, der sich nicht zuletzt auch gegen die brutale Unterdrückung des Christentums durch die Zoroastrier richtete. Der armenische Aufstand im Norden begann deshalb so verheißungsvoll, weil starke Truppenverbände des Großkönigs im Osten wegen der Hunnengefahr dauerhaft gebunden waren. Doch nach Peroz' Rückkehr Anfang der siebziger Jahre hatten nicht nur Armenier ${ }^{35}$ und Georgier, sondern auch die Christen im Sasanidenreich unter dem Zorn des Großkönigs schwer zu leiden. Bezeichnenderweise konnte Barsauma in dieser brenzligen Situation seine eigene Position nicht nur halten, sondern dank seiner hervorragenden Kontakte zum ortsansässigen Marzpan sogar ausbauen. Prominentes Opfer der von Peroz initiierten Verfolgung wurde der Katholikos-Patriarch Babowai, der offiziell wegen Hochverrats interniert wurde.

${ }^{31}$ Vgl. die ep. 2 bei СНАВОт, Synodicon Orientale (wie Anm. 4), 526-529. Barsauma hatte freilich die Neigung, sich beim Marzpan unentbehrlich zu machen und kokettiert in der Korrespondenz gerne mit seinen Beziehungen.

${ }^{32}$ So die nestorianische Chronik von Seert (PO VII/2,101).

${ }^{33} \mathrm{Zu}$ diesem Großkönig vgl. TH. NÖLDEKE, Geschichte der Perser und Araber zur Zeit der Sasaniden. Aus der arabischen Chronik des Tabari, Leiden 1879, (repr. Leiden 1973), 114-132; SCHIPPMANN, Grundzüge (wie Anm. 25), 43-45.

${ }^{34}$ Die arabischen Quellen des Tabari, vgl. NÖLDEKE (wie Anm. 33), 118-122, sprechen von einer siebenjährigen Hungersnot aufgrund langer Dürre, welcher der Großkönig durch großzügige Steuernachlässe zu steuern suchte.

${ }^{35}$ Nach Thomas von Erzerun, zit. nach BRAUN, Synodicon Orientale (wie Anm. 4), 61, Anm. 2, fing Barsauma auch Briefe des armenischen Katholikos ab und lieferte sie dem Großkönig aus. 
Folgt man der Darstellung der Ereignisse in der Chronik von Seert ${ }^{36}$, so war Barsauma an der Eskalierung dieser traurigen Entwicklung nicht ganz unbeteiligt. Auf dem Höhepunkt der Verfolgung Ende der siebziger Jahre, die sich vor allem auf den Großraum Seleukia-Ktesiphon konzentrierte, sandte der Katholikos einen verzweifelten Hilferuf aus dem Kerker an den byzantinischen Kaiser Zenon (474-475. 476-491) in der freilich eitlen Hoffnung, der monophysitenfreundliche Monarch werde für die persische Christenheit in gleicher Weise intervenieren wie seiner Zeit Konstantin gegenüber Schapur II. Die Häscher des Bischofs und Grenzwächters Barsauma erfuhren zufällig von dem geplanten Komplott und fingen den Boten, einen niederen Kleriker, der den gesiegelten Brief im Schaft seines Wanderstabes ${ }^{37}$ verborgen hatte, ab. Der übereifrige Bischof von Nisibis hatte nun nichts Eiligeres zu tun, als das kompromittierende Schreiben seines Vorgesetzten in die Hände des Großkönigs zu spielen, der nun unverzüglich dem unglücklichen Babowai den Proze ${ }^{38}$ wegen Hochverrats machen ließ. Da der Katholikos im Verlaufe der Verhandlungen nicht bereit war, dem christlichen Glauben zu entsagen und nach Zoroastermanier Sonne und Feuer anzubeten, wurde er grausam gefoltert und schließlich außerhalb der Hauptstadt erhängt. Der Leichnam dieses Blutzeugen wurde von den anwesenden Gläubigen in der Beduinenstadt Al-Hira ${ }^{39}$ (unweit des späteren Kufa) ehrenvoll bestattet.

Die Verfolgung unter Peroz stürzte die persische Kirche in tiefe Verwirrung. Chaotische Verhältnisse in der Regierungszeit des Katholikos Babowai (465-484) waren nach Aussage der Chronik von Seert ${ }^{40}$ die Folge. Zweifel an der Führungskompetenz des Bischofs von Seleukia-Ktesiphon wurden schon vor seiner Verhaftung geäußert, doch brach die kirchliche

${ }^{36} \mathrm{PO}$ VII/2,101f.

${ }^{37}$ Dieses Beispiel sollte später Schule machen. Im sechsten Jahrhundert waren es wiederum listenreiche nestorianische Mönche, welche die Eier der Seidenraupe in ausgehöhlten Wanderstecken von China nach Byzanz schmuggelten, vgl. N. PIGULEWSKAJA, Byzanz auf den Wegen nach Indien. Aus der Geschichte des byzantinischen Handels mit dem Orient vom 4. bis 6. Jahrhundert, Berlin 1969, $158 \mathrm{f}$.

${ }^{38}$ Zum Martyrium des Babowai vgl. auch GeRÖ, Barsauma (wie Anm. 2), 97-109. Die syrische Ausgabe der Akten besorgte P. BEDJAN, Acta martyrum et sanctorum syriace II, Leipzig 1891, (repr. Hildesheim 1968), 631-634.

${ }^{39} \mathrm{Vgl}$. PO VII/2,102. Al-Hira war seit 410 Bischofssitz und bis zum Einfall der muslimischen Araber im siebten Jahrhundert Zentrum der nestorianischen Arabermission. Zur Geschichte vgl. G. ROTHSTEIN, Die Dynastie der La'miden in Al-Hîra. Ein Versuch zur arabischpersischen Geschichte zur Zeit der Sasaniden, Berlin 1899, (repr. Hildesheim 1968).

${ }^{40} \mathrm{PO}$ VIII/2,99f. 
Ordnung während seiner jahrelangen Haft, in der er die Amtsgeschäfte nur eingeschränkt führen konnte, völlig zusammen: Bischöfe wurden ohne Zustimmung des Katholikos installiert und konnten nur mit Mühe und unter Aufwendung größerer finanzieller Mittel aus ihren Ämtern wieder entfernt werden. Laien rissen gar priesterliche Vorrechte in der Sakramentenspendung an sich oder installierten eigenhändig Bischöfe ihrer Wahl. Liturgische Bestimmungen wurden nicht eingehalten, und die Klerikerzucht, besonders die Enthaltsamkeit der Priester und Mönche, ließ sehr zu wünschen übrig: Schändliches Treiben wurde eingefübrt; die Unzucht nabm zu und auch die widerrechtliche Heirat unter Mönchen und Prie$s t e r n^{41}$. Exkommunizierte Laien verschafften sich widerrechtlich Zugang zu den Sakramenten. Die Opposition gegen den Katholikos wuchs von Tag zu Tag und schlug 483/484 in eine offene Revolte um. Als Inhaber des drittwichtigsten Metropolitansitzes, nämlich des Stuhles von Nisibis, tat sich Barsauma mit dem zweitwichtigsten Hierarchen, dem Metropoliten von Beth-Lapat (Gundeschapur) ${ }^{42}$, zusammen, um den Katholikos gemeinsam auf einer Bischofssynode im Frühjahr $484^{43}$ zu stürzen.

\section{Die synodalen Entscheidungen}

\subsection{Die Synode von Beth-Lapat (484)}

Die Akten der Synode von Beth-Lapat ${ }^{44}$ sind bis auf wenige Fragmente, die auf späteren Synoden zitiert und bestätigt werden - hier wäre in unserem Zusammenhang besonders die Synode des Katholikos Babai (Seleukia-Ktesiphon 497) zu nennen -, verloren. Angesichts der skandalösen Vorgänge um Barsauma und Babowai verwundert es wenig, daß das offi-

${ }^{41} \mathrm{PO} \mathrm{VII} / 2,99 \mathrm{f}$.

${ }^{42} \mathrm{Daß}$ die Quellen den Patriarchalvikar, den Metropoliten von Kaschkar, nicht erwähnen, hängt wohl mit dem Umstand zusammen, daß dieser ein Parteigänger des Babowai war; zur Hierarchie der mesopotamischen Sitze infolge der Synode von 410 vgl. auch P. BRUNS, Bemerkungen zur Rezeption des Nizänums in der ostsyrischen Kirche, in: AHC 32 (2000) 122, bes. 21f.

${ }^{43}$ Die Quellen [СНАвот, Synodicon Orientale (wie Anm. 4), 63. 210] nennen den Frühlingsmonat Nisan (April) im 27. Regierungsjahr des Peroz (484) als Datum.

${ }^{44}$ Beth-Lapat, pers. Gundeschapur (Schapurs Heerbaufe), war eine der Residenzstädte der Großkönige und galt als bedeutendes kulturelles Zentrum in der Sasanidenzeit, vgl. SCHIPPMANN, Grundzüge (wie Anm. 25), 113. Schon Schapur I. holte griechische Ärzte in die Stadt, Schapur II. siedelte syrische Handwerker und römische Kriegsgefangene, nicht selten Christen, an und gründete eine Universität mit einer berühmten medizinischen Fakultät, zur Etymologie von Gundeschapur vgl. auch NÖLDEKE (wie Anm. 33), 40-42. 
zielle Synodicon Schweigen über die verwickelten Aktivitäten des Jahres 484 breitet und erst wieder mit der regulären Patriarchalsynode von Seleukia-Ktesiphon (486) neu beginnt. Die Beschlüsse von 484 wurden kassiert; die gängigen Handschriften bieten daher die wenigen vorhandenen Textfragmente lediglich im Anhang ${ }^{45}$. Die Tilgung aus dem Gedächtnis der persischen Kirche gelang jedoch glücklicherweise nicht vollständig. Monophysitische wie nestorianische Chronisten bieten den einen oder anderen nicht unbedeutenden Überlieferungssplitter. Auch erscheint der Versuch, die Teilnehmerliste der Synode zu rekonstruieren, nicht von vornherein aussichtslos, da Barsauma zusammen mit den übrigen Synodenvätern 486 schriftlich Abbitte ${ }^{46}$ für seinen Frevel leistete, die Beschlüsse von 484 öffentlich widerrief und sich der Großmut des neugewählten Katholikos Aqâq unterwarf.

Bei der Synode von Beth-Lapat ${ }^{47}$ war der Ortsbischof nicht zugegen, so daß Barsauma als ranghöchster Hierarch frei agieren konnte. Der erste Tagesordnungspunkt war die Absetzung des noch amtierenden, im Kerker schmachtenden Katholikos Babowai wegen Vernachlässigung der Amtspflichten ${ }^{48}$ und die Wahl eines neuen Patriarchen. Die Anhänger Babowais waren in der Minderheit und wurden überstimmt. Der Katholikos galt nunmehr als amtsenthoben; noch im Gefängnis verhängte er den

${ }^{45}$ CHABOT, Synodicon Orientale (wie Anm. 4), 525, führt mit Bezugnahme auf die Angaben des Kompilators (308) aus, daß die Akten des Barsauma und seiner Anhänger wegen Irregularität getilgt wurden. Die Korrespondenz des Barsauma wurde erst nachträglich in die römische Handschrift eingefügt. Chabot hat die bei den Vätern überlieferten Synodenfragmente im Anhang ediert (ebd. 621-625). Vgl. auch den summarischen Bericht im Synodicon (61. 308f) über die Aussöhnung zwischen Aqâq (Acacius) und Barsauma. Dt. Übersetzung der Barsauma-Briefe bei BRAUN, Synodicon Orientale (wie Anm. 4), 74-83.

${ }^{46} \mathrm{Vgl}$. dazu СНАВОТ, Synodicon Orientale (wie Anm. 4), 525; 531, Anm. 4; zur Rekonstruktion der Unterschriftenliste im einzelnen vgl. GERÖ, Barsauma (wie Anm. 2), 42-44.

${ }^{47}$ Bei der Interimssynode von Beth-'Idrai im Herbst 485 sowie bei der Patriarchalsynode von 486 wird ein gewisser Pâpâ als Metropolit von Beth-Lapat erwähnt, vgl. GERÖ, Barsauma (wie Anm. 2), 42. Möglicherweise war der Bischofssitz 484 vakant, oder Pâpâ war bereits installiert, wollte sich aber nicht direkt gegen den Katholikos stellen und zog es daher vor, die Teilnahme zurückzuziehen. Zur kirchenpolitischen Rolle des Barsauma vgl. ebd., 73-78.

${ }^{48}$ Ebd., 38, Anm. 70, vermutet simonistische Aktivitäten des Katholikos. Leider fehlen in der Chronik von Seert (PO VII/2,99) die ersten Zeilen der Babowai-Geschichte. Es heißt dort, er habe von ihnen (den Bischöfen? den Leuten?) viel Vermögen erhalten. Der Chronist schreibt: In seinen Tagen nabm die Verwirrung $z u$, und die Dinge gerieten durcheinander. Männer und Frauen machten sich einen Spaß daraus, die Fübrer selbst zu wäblen, und spendeten Bestechungsgeld für ibre Handauflegung (ebd.). 
Bann $^{49}$ über die illegitime Versammlung. Barsauma hatte freilich seine Möglichkeiten stark überschätzt, wenn er geglaubt hatte, er könnte sich des nunmehr vakanten Stuhles bemächtigen. Bei der entscheidenden Abstimmung versagte die Mehrheit des Episkopats dem ambitionierten Kirchenmann die Unterstützung und wählte überraschend einen Verwandten des Babowai, Bischof Aqâq (lat. Acacius), einen gediegenen Theologen, der seine Studien gleichfalls in der Perserschule von Edessa absolviert hatte. Aqâq hatte zweifelsohne den Segen des mit der Gloriole des Martyriums umgebenen, scheidenden Katholikos. Er war ein Mann des Ausgleichs und daher noch am ehesten geeignet, den Zusammenbruch der Kircheneinheit zu verhindern. Barsaumas Enttäuschung über die Entwicklung der Dinge war groß; er drohte mit dem Schisma und unterwarf sich erst nach zähen Verhandlungen anderthalb Jahre später, im Herbst 485, dem neuen Katholikos. Kurz nach Beendigung der Synode von Beth-Lapat starb auch Barsaumas politischer Gönner. Der Großkönig Peroz fiel auf seinem letzten unglücklichen Feldzug gegen die Hephthaliten im Osten des Reiches (bei Balch?) ${ }^{50}$, im heutigen Afghanistan, was von den christlichen Chronisten als Fingerzeig Gottes ${ }^{51}$ gedeutet wurde. Monophysitischen Quellen ${ }^{52}$ zufolge soll Peroz Barsauma zum Katholikos eingesetzt haben. Dies entspricht kaum den historischen Tatsachen. Es mag zwar Barsaumas Wunsch gewesen sein, doch wurden seine Pläne durch den unglücklichen Tod des Großkönigs vereitelt. Gleichwohl gewann er das Vertrauen von Peroz' Nachfolger Balâsch $(484-488)^{53}$, das er sich jedoch mit seinem Widersacher Aqâq teilen mußte.

${ }^{49} \mathrm{Vgl}$. PO VII/2,100. Im arab. Text findet sich ein über das Syrische eingedrungenes

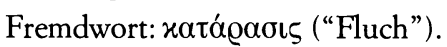

${ }^{50}$ Vgl. NÖLDEKE, (wie Anm. 33), 123-132. Zur Lokalisierung der Schlacht vgl. ebd., 123, Anm. 4. Den Warnungen seiner Militärberater zum Trotz hatte sich Peroz in einen Hinterhalt locken lassen, wo er die technische und zahlenmäßige Überlegenheit seiner Truppen nicht ausspielen konnte. Der Feldzug endete in einem Desaster: Peroz fiel, seine Tochter, der Großpriester und ein Teil seines Harems sowie des Kronschatzes wurden zur Beute der Aufständischen. Infolge der persischen Schwäche drangen die Hephthaliten verstärkt in die östlichen Provinzen ein.

${ }^{51}$ Vgl. PO VII/2,107f. In der christlichen Hagiographie erscheint Peroz in einer Reihe mit den biblischen Frevelkönigen wie dem Pharao, Nebukadnezar, Saul und Sanherib, die von Gott ihre gerechte Strafe für ihre Sünden erhalten.

${ }^{52}$ Marutha von Takrit bei Michael dem Syrer, vgl. dazu GERÖ, Barsauma (wie Anm. 2), 37, Anm. 58.

53 So wurde Barsauma nach Balâschs Regierungsantritt in diplomatischer Mission nach Konstantinopel entsandt, vgl. dazu GERÖ, Barsauma (wie Anm. 2), 37, Anm. 63. Balâsch, ein 
Die Synode von Beth-Lapat hatte Barsauma zu Ende bringen können, wenn auch aus seiner Sicht nicht in allen Punkten erfolgreich. Die vorhandenen Kanonfragmente ${ }^{54}$ behandeln mit einer einzigen Ausnahme rein disziplinäre Fragen. Zwei Auszüge bei Elias von Nisibis verwerfen die Simonie $^{55}$ - ein Vorwurf, der gegen Babowai erhoben worden war -, ein weiterer Kanon untersagt die Mitsprache des byzantinischen Kaisers bei der Metropolitenwahl ${ }^{56}$, andere Entscheidungen behandeln die Ehehindernisse bei Blutsverwandtschaft ${ }^{57}$ und verwerfen die Vielweiberei ${ }^{58}$. Dogmengeschichtlich bedeutsam ist ein weiteres Fragment ${ }^{59}$, das den angefeindeten Theodor von Mopsuestia gegen den Häresievorwurf in Schutz

Bruder des Peroz, war freilich ein Herrscher ohne große Machtbefugnisse. Die Regierungsgeschäfte wurden vielmehr von den mächtigen Großvasallen geführt, vgl. SCHIPPMANN, Grundzüge (wie Anm. 25), 45.

${ }^{54}$ Vgl. dazu GERÖ, Barsauma (wie Anm. 2), 79-88.

${ }^{55}$ Vgl. CHABOT, Synodicon Orientale (wie Anm. 4), 621f. Barsaumas Absage an die Simonie erscheint angesichts der eigenen Bestechungsversuche mehr als fragwürdig, s. o., Anm. 26.

${ }^{56} \mathrm{Vgl}$. СНАBOT, Synodicon Orientale (wie Anm. 4), 621f. Die Einmischung von außen wurde vor allem im römisch-persischen Grenzgebiet zu einem ernsten Problem. Doch stellte die Beeinflussung durch die persischen Behörden eine keineswegs geringere Gefahr für die Kirchenfreiheit dar.

${ }^{57}$ Vgl. ebd., 623f. Die Synode beklagt, daß viele Christen, offensichtlich Konvertiten aus dem Zoroastrismus, die Bräuche der Magier hinsichtlich der Verwandtenehe beibehielten. Kleriker wurden unter Androhung der Suspension angehalten, keine pastoralen Kompromisse zu dulden. Die Chronik von Seert, PO VII/2,100, berichtet konkret, daß die Synode die Heirat mit der Frau des Vaters oder der des Bruders untersagt habe. Auf den gesellschaftlichen Hintergrund kann hier nicht näher eingegangen werden. Es ist sehr zu bedauern, daß die Darstellung bei SCHIPPMANN, Grundzüge (wie Anm. 25), kein Kapitel zu Ehe und Familie enthält. Nach A. CHRISTENSEN, L'Empire des Sassanides. Le peuple, l'état, la cour, Kopenhagen 1907, 53, ging es bei dem im Awesta vorgeschriebenen und vor allem von den Adeligen geübten Brauch der Verwandtenehe um die pureté du sang.

${ }^{58}$ CHABOT, Synodicon Orientale (wie Anm. 4), 623f. Die Männer werden auf die Schöpfungsordnung sowie die Anweisung Christi und seiner Apostel verwiesen und ermahnt, sie sollten sich mit einer einzigen Frau begnügen und keine zusätzliche Konkubine halten. In einem weiteren Kanon wird der Frauenraub verurteilt. Die derart zustande gekommenen Ehen sind als ungültig zu betrachten. Frauenräuber bleiben von der Kommunion ausgeschlossen, (vgl. ebd., 624f). Man hat hier an diverse Praktiken der vorislamischen Araber zu denken, aber auch am Hof des Großkönigs waren christliche Frauen als Beutegut keine Seltenheit. Nach CHRISTENSEN, L'Empire des Sassanides (wie Anm. 57), 52f, konnte sich der persische Mann zwei privilegierte Frauen, die zu gleichen Teilen erbberechtigt waren, nehmen, oder aber er hatte eine privilegierte Frau und eine weitere "adoptierte" bzw. eine "Dienerin", die allerdings nicht voll erbberechtigt war.

${ }^{59}$ Zitiert auf der Synode Gregors I. 605, vgl. CHABOT, Synodicon Orientale (wie Anm. 4), 211. 476. 
nimmt und ihn gleichsam zum authentischen Lehrer der Kirche des Ostens erhebt. In der monophysitischen Tradition ${ }^{60}$ wird Barsauma außerdem die Aufhebung der Klerikerenthaltsamkeit zugesprochen. Er habe schmutzige Kanones (qânône țampe) in Kraft gesetzt und beschlossen, daß kein Priester, Diakon oder Bischof unbeweibt sein dürfe, so daß er wegen seines eigenen Hurenweibes nicht getadelt werden konnte ${ }^{61}$. Demnach hätte Barsauma aus unlauteren Motiven, nämlich um seine eigene Unkeuschheit mit der abtrünnigen Bundestochter Mâmôêt ${ }^{62}$, die er nach 486 offiziell heiratete, zu vertuschen, den Klerikern die Heirat nicht nur freigestellt, sondern jene sogar in die Ehe gedrängt, was freilich eine Übertreibung aus monophysitischer Sicht darstellen dürfte. Daß Barsauma trotz seines hohen Alters (nach Gerös Chronologie wäre er weit über achtzig gewesen!) eine abtrünnige Bundestochter geheiratet hat, ist historisches Faktum, das selbst von nestorianischen Chronisten ${ }^{63}$ nicht bestritten, vielmehr als Peinlichkeit unter vielen Ausflüchten ${ }^{64}$ entschuldigt wird, eignete sich doch gerade dieses Thema vorzüglich für die konfessionelle Polemik. In der Kontroverstheologie des sechsten Jahrhunderts wird nämlich vor allem bei monophysitischen ${ }^{65}$, aber auch melkitischen ${ }^{66}$ Chronisten der Glaubensabfall der persischen Kirche zum "Nestorianismus" mit dem Nachlassen der Klerikerenthaltsamkeit begründet. Selbst in den

${ }^{60} \mathrm{Vgl}$. dazu die Quellendiskussion bei GerÖ, Barsauma (wie Anm. 2), 46, Anm. 122.

${ }^{61}$ Marutha von Tagrit, zitiert bei Michael dem Syrer (J. B. СНАBOT, Chronique de Michel le Syrien, patriarche jacobite d'Antioche IV, Paris 1910, (repr. Brüssel 1963), 426).

${ }^{62}$ Zum Namen vgl. GerÖ, Barsauma (wie Anm. 2), 57, Anm. 188. Barhebräus, chron. eccl., 73, nennt Mamoe die Syneisakte ('âmortâ = cobabitatrix) des Barsauma. Man darf vermuten, daß es dem Bischof um eine nachträgliche Legitimation einer bis dato ungesetzlichen Verbindung ging. Armenische Historiker wie Moses von Choren, hist. III,64, und Lazarus v. Pharpi, hist. 15, führen genüßlich aus, wie der vom Großkönig Bahram V. eingesetzte Gegenpatriarch zusammen mit seinen Klerikern nach syrischem Brauch in Begleitung einheimischer Weiber nach Armenien gekommen sei, vgl. dazu Braun, Synodicon Orientale (wie Anm. 4), 61, Anm. 1, der von einer laxen Observanz der Syrer in puncto Klerikerenthaltsamkeit ausgeht. Zur Datierung der Stelle s. u. den Exkurs.

${ }^{63}$ Vgl. GeRÖ, Barsauma (wie Anm. 2), 82f. Sowohl die Chronik von Seert als auch die Chronisten Mari und Amr erachteten den bischöflichen Zölibat als normativ, vgl. ebd., 83, Anm. 25; daher rührt auch ihre besondere Abneigung gegenüber Barsauma.

${ }^{64}$ Mari meint, Barsauma habe unter Druck des Königs gehandelt, eine nie vollzogene Scheinehe geführt, um Mamoe vor einer drohenden Enterbung zu bewahren, vgl. die Belege im einzelnen bei GERÖ, Barsauma (wie Anm. 2), 82f.

${ }^{65}$ Vgl. hierzu S. UHLIG, Ein syrisches Fragment über die "Nestorianisierung" Persiens, in: OrChr 72 (1988) 68-81.

${ }^{66}$ So bei Leontius von Byzanz (PG 86,1369B). 
persischen Märtyrerakten ${ }^{67}$ spiegelt sich diese Situation indirekt wider. Die disziplinarische Frage war zu jener Zeit so eng mit der dogmatischen verknüpft, daß die Enthaltsamkeit zum äußeren Signum der monophysitischen Orthodoxie werden konnte. Auch wenn kein explizit antiasketischer Kanon der Synode von Beth-Lapat überkommen ist - was uns angesichts der prekären Quellenlage nicht ernstlich verwundern $\mathrm{kann}^{68}$, so ist doch mit großer Wahrscheinlichkeit davon auszugehen, daß ein solcher Beschluß zur Aufhebung der Klerikerenthaltsamkeit bereits 484 gefaßt wurde. Dies wird nicht zuletzt durch die Akten der Synode des Babai (497) nahegelegt, welche die Annullierung der Kanones von 484 ausdrücklich bekräftigt, gleichzeitig aber auch die Aufhebung der Klerikerenthaltsamkeit erneut bestätigt ${ }^{69}$. Die nestorianische Chronik von Seert datiert Barsaumas antiasketische Aktivitäten offensichtlich auf die Zeit nach der Synode von Beth-Lapat (484), wenn es dort heißt: Barsauma, der Metropolit von Nisibis, verfaßte ein Schreiben, in dem er den Zönobiten und Priestern, welche sich nicht enthalten konnten, die Heirat gestattete. Er nabm das Wort des Paulus zum Vorwand: "Es ist besser für die Menschen zu beiraten, als vor Begierde zu brennen" 70 .

Wir wissen nicht, in welcher Vollmacht Barsauma dieses Schreiben, arab. kitâban (nach Mari war es ein Synodalschreiben), aufsetzte, ob es nur für seine Metropolie galt oder für die gesamte persische Kirche, wahrscheinlich tat er es in dem übersteigerten Bewußtsein, daß er als der rechtmäßige Katholikos für alle ihm unterstellten Bischöfe weisungsbefugt sei. Gerö ${ }^{71}$ vermutet, daß es Barsauma lediglich um eine Lockerung der Dispenspraxis gegangen sei, doch widerspricht einer solchen Vermutung

${ }^{67}$ Als typisch mag eine Episode aus den persischen Märtyrerakten gelten (BRAUN, BKV ${ }^{2}$ 22,257). Unter dem Katholikat Gregors I. fand 612/13 eine Disputation zwischen den Severianern und Nestorianern in der königlichen Residenz statt. Irritiert von Glaubensspaltungen unter den Christen, fragt der Großkönig, wer denn recht habe, die Nestorianer oder die Mönche (sic!). Obwohl es zu dieser Zeit sicherlich nestorianische Mönche gab (etwa den Märtyrer Georg), wird die monophysitische Sache von den Außenstehenden gänzlich mit dem Asketentum identifiziert. Bemerkenswert ist ferner, daß die offizielle Antwort des Synodicon, vgl. СНАВОТ, Synodicon Orientale (wie Anm. 4), 574, wiederum gegen die Mönche gerichtet ist.

${ }^{68}$ Gegen GerÖ, Barsauma (wie Anm. 2), 46.

${ }^{69}$ S. u. Abschnitt 2.3.

${ }^{70} \mathrm{PO}$ VII/2,100f.

${ }^{71}$ GERÖ, Barsauma (wie Anm. 2), 81, spricht von "orderly dispensation from vows" und bestreitet Barsaumas Zugehörigkeit zu einer antiasketischen Bewegung, ebd., 82f. 
der "revolutionäre" Geist des Metropoliten von Nisibis ${ }^{72}$ ebenso wie der spätere Gang der Ereignisse. Barsauma hatte größere Pläne für die Umgestaltung der persischen Kirche, doch war er 484 nicht zum Katholikos gewählt worden und verfügte daher nicht über die notwendigen kirchenpolitischen Mittel.

Eine weitere Frage, die sich in diesem Zusammenhang stellt, ist die, welche Gründe für den Ausbruch der Streitigkeiten zwischen Barsauma und Babowai ${ }^{73}$ verantwortlich waren. Beide Kirchenmänner hegten schon seit geraumer Zeit eine intensive Abneigung gegeneinander, die durch Barsaumas antiasketische Aktivitäten noch vertieft wurde. Babowa ${ }^{74}$ war persönlich ein integrer, frommer Bischof, der unter dem Einfluß gewisser Mönche vom Zoroastrismus zur christlichen Religion konvertiert war, was ihn in natürlichen Gegensatz zum Großkönig Peroz brachte. Seine theologische Formung erhielt der Katholikos gleichfalls in monastischen Zirkeln und blieb selbst noch als Bischof ein gestrenger Mönchsvater, der das asketische Ideal hochhielt und publizistisch verteidigte. Über die von Barsauma angestrebten Neuerungen hinsichtlich der Klerikerenthaltsamkeit war er sicherlich nicht besonders begeistert, doch waren ihm während der jahrelangen Kerkerhaft ${ }^{75}$ buchstäblich die Hände gebunden. Als pastoraler Manager der Großkirche hatte Babowai gewiß seine Schwächen, als Bekennerbischof war sein Status innerhalb der persischen Kirche geradezu sakrosankt. Insofern werten selbst die nestorianischen Chronisten Barsaumas Attacken gegen den Katholikos als unverzeihlichen Affront. $\mathrm{Daß}$ es nicht schon 484 zu einer definitiven Änderung der Klerikerdiszi-

${ }^{72}$ Gerö hält Barsauma für den "spokesman and ideologue of the democratic party" innerhalb des persischen Episkopats (ebd., 39). Doch ist dies blanker Unfug, da der Metropolit von Nisibis nirgends den hierarchischen Charakter der Kirche infrage stellt. Eher könnte man bei Barsauma von einer Überbetonung des kollegialen Prinzips gegenüber dem papalen sprechen, das spätestens seit 410 mit dem Bischofssitz von Seleukia-Ktesiphon verknüpft ist. Als Metropolit wußte Barsauma seine Rechte freilich zu wahren, ob er als Katholikos kollegial regiert hätte, wenn er 484 gewählt worden wäre, ist mehr als fraglich. Zur Stellung der persischen Metropoliten und des Katholikos vgl. W. SELB, Orientalisches Kirchenrecht I. Die Geschichte des Kirchenrechts der Nestorianer von den Anfängen bis zur Mongolenzeit, Wien 1981, 115-136. Barsauma war ein ziemlich unausgeglichener Charakter, der generell Schwierigkeiten mit jeder Autorität hatte, die nicht seine eigene war, das Verhältnis zur kirchlichen Obrigkeit blieb daher zeitlebens gespannt, vgl. GERÖ, Barsauma (wie Anm. 2), 54f. 73-78.

${ }^{73}$ Vgl. ebd., 38.

${ }^{74}$ Vgl. dazu Baumstark, Geschichte (wie Anm. 27), 107.

${ }^{75}$ Nach Dadischo sollen es sieben Jahre (AMS II, 631, Anm. 1) gewesen sein, doch könnte diese Zahl symbolischen Charakter haben. 
plin in der persischen Kirche kam, ist allein auf den Umstand zurückzuführen, daß die Synodenbeschlüsse von Beth-Lapat annulliert wurden und zunächst keine Auswirkungen zeitigten, abgesehen von dem durch Barsauma versandten Schreiben. Der Metropolit von Nisibis hatte indes durch seine Umtriebigkeit die Weichen für jene Entwicklungen gestellt, die zwei Jahre später auf der Patriarchalsynode von SeleukiaKtesiphon (486), diesmal jedoch offiziell, zum Durchbruch kommen sollten.

\subsection{Die Kanones des Aqâq (486)}

Die Regierung des Aqâq (lat. Acacius; 485-496) ist durch die offizielle Aufhebung der Klerikerenthaltsamkeit, die Erhebung Theodors zum Kirchenlehrer und ständige Reibereien mit Barsauma ${ }^{76}$ geprägt. Alle genannten Ereignisse stehen nicht in einem kausalen Zusammenhang. Der Konflikt zwischen Barsauma und Aqâq war rein persönlicher Natur und entzündete sich weniger an theologischen Sachfragen. Auf der Provinzsynode von Beth-'Idrai ('Adrai) Ende August oder Anfang September 48577 gelang es Aqâq, den nordmesopotamischen Episkopat hinter sich zu scharen. Die Beschlüsse von Beth-Lapat wurden annulliert ${ }^{78}$, und Barsauma unterwarf sich zähneknirschend dem neuen Katholikos. Der renitente Bischof weigerte sich trotz schriftlicher Aufforderung des Katholikos, im Winter, Anfang Februar $486^{79}$, an der Patriarchalsynode in Seleukia-Ktesiphon teilzunehmen, obgleich er auf die Unterstützung zumindest eines Teils des Epikopats ${ }^{80}$ zählen konnte. Was nun folgte, war allein das Werk des Aqâq und seiner Genossen, die weder in der Festigung des "Theodo-

${ }^{76}$ Die letzten Lebensjahre dieses unruhigen Geistes brauchen uns hier nicht zu beschäftigen, vgl. GERÖ, Barsauma (wie Anm. 2), 54-59. Von Altersmilde ist nirgends etwas zu spüren, im Gegenteil, am Ende hatte sich der Bischof auch noch mit Narsai, dem Leiter der Theologenschule von Nisibis, der Barsaumas Haltung gegenüber dem Katholikos mißbilligte, vgl. ebd., 91, Anm. 22, heillos zerstritten.

${ }^{77}$ Vgl. ebd., 50f. Die unschönen Vorwürfe, die Barsauma gegen Aqâq erhob, können wir hier übergehen. Beth-'Idrai (oder auch Beth-'Adrai) liegt etwa $65 \mathrm{~km}$ nördlich von Mossul in der Nähe von Alqosch an der Hauptstraße von Nisibis nach Seleukia-Ktesiphon.

${ }^{78}$ Barsauma hat diese Beschlüsse brieflich bekräftigt, vgl. СНABOT, Synodicon Orientale (wie Anm. 4), 526. 534.

${ }^{79}$ Die Väter kamen im Monat Schevat (Ende Januar/Anfang Februar) im zweiten Regierungsjahr des Balasch zusammen, vgl. ebd., 54.

${ }^{80}$ Vgl. die Liste der Freunde Barsaumas bei GERÖ, Barsauma (wie Anm. 2), 52, Anm. 159. 
rianismus" noch in der Aufhebung der Klerikerenthaltsamkeit von Barsauma ${ }^{81}$ gezwungen worden waren.

$\mathrm{Zu}$ den Teilnehmern und Unterzeichnern der Synode von SeleukiaKtesiphon zählen u. a. die bei Simeon von Beth-Arscham erwähnten edessenischen Theologen ${ }^{82}$, jene Studienkollegen Aqâqs also, welche inzwischen zu Bischöfen avanciert waren. Durch eine geschickte Personalpolitik hatte bereits Aqâqs Vorgänger die vakanten Sitze im Westen des Perserreiches mit ihm ergebenen, die Sache des Theodor von Mopsuestia verteidigenden Theologen besetzt und so zur "Nestorianisierung" der Region beigetragen.

Aus c. 1 der Synode des Aqâq (486) spricht die Furcht der Väter vor einer schleichenden Unterwanderung der nördlichen Provinzen, besonders der Adiabene, durch monophysitische Mönche. Bereits die Provinzsynode von Beth-'Idrai hatte sich mit dem Phänomen beschäftigt, daß geistesgestörte Leute, welche das Büßergewand tragen, wider die Ökonomie unseres Herrn lästern ${ }^{83}$, und deshalb die theopaschitische Häresie feierlich verworfen, ein Anathem, das in Seleukia-Ktesiphon nun ausdrücklich erneuert wird. Offensichtlich hatte die Reform des Rabbula ${ }^{84}$ durchschlagenden Erfolg nicht nur in Edessa gehabt, sondern auch im gesamten nordmesopotamischen Raum ausgestrahlt. Nicht nur doktrinäre Fragen nach der orthodoxen Christologie wurden angeschnitten, auch der überbordende Asketismus der Messalianer sollte, wie aus der Deutung von

${ }^{81}$ Auch BRAUN, Synodicon Orientale (wie Anm. 4), 63, nimmt an, daß Aqâq keineswegs von Barsauma zur Annahme des Nestorianismus und zur Aufhebung der Klerikerenthaltsamkeit gezwungen wurde.

${ }^{82}$ Vgl. die Listen ebd., 64f. 73f; BRUnS, "Perserschule" (wie Anm. 8).

${ }^{83} \mathrm{Vgl}$. Braun, Synodicon Orientale (wie Anm. 4), 66f; СНАBOT, Synodicon Orientale,

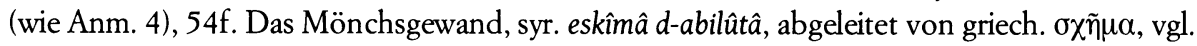
lat. habitus, bestand aus einer schwarzen Kukulle mit Kapuze; vgl. zum persischen Mönchtum auch die Studie von M. TAMCKE, Der Katholikos-Patriarch Sabrischo I. (596-604) und das Mönchtum, Frankfurt 1988, bes. 23-26.

${ }^{84}$ Über den Mönchsbischof und Ketzerhammer vgl. BLUM, Rabbula (wie Anm. 22), 81106. Auffallend ist, daß der Bischof von Edessa die Gruppe der Messalianer äußerst taktvoll behandelte, vielleicht weil er ihrem asketischen Rigorismus nicht gänzlich abgeneigt war. Als Kirchenpolitiker setzte er sich für eine strenge cyrillische Orthodoxie auch im syrischen Hinterland von Edessa ein, vgl. ebd., 152-207; P. BRUNS, Die Kanones des Rabbula ( $†$ 435) und ihr Beitrag zur Reform des kirchlichen Lebens in Edessa, in: H. REINHARD (Hg.), Theologia et Jus Canonicum. FS H. Heinemann, Essen 1995, 471-480. 
1 Tim 4,18 ${ }^{85}$ hervorgeht, abgewehrt werden. C. 2 der Synode des Aqâq $(486)^{86}$ erweckt den Eindruck, daß der Monophysitismus gerade in den ländlichen Regionen unaufhaltsam auf dem Vormarsch war, während das nestorianische Bekenntnis sich vornehmlich auf die größeren Städte beschränkte. Schwarzgekleidete Mönche übten gerade auf die schlichten Gläubigen eine unwiderstehliche Anziehungskraft aus und machten den Nestorianern ganze Gemeinden abspenstig. In diesem Kontext ist nun das Bemühen der Synodenväter zu sehen, den Mönchsklerus gänzlich aus den Pfarreien zu entfernen ${ }^{87}$ und durch einen verheirateten Seelsorgsklerus ${ }^{88}$ $\mathrm{zu}$ ersetzen. Die Mönche werden unwiderruflich in die Klöster und die unwirtlichen Gegenden verbannt. Zuwiderhandelnde Priester werden mit der Suspension, Laien mit dem Ausschluß von der Kommunion bestraft.

Als äußeren Anlaß für die Aufhebung der Klerikerenthaltsamkeit nennt c. 3 die geringe soziale Akzeptanz der Ehelosigkeit in der heidnisch-persischen Gesellschaft ${ }^{89}$ sowie die Skandalgeschichten abtrünniger Kleriker, welche die Öffentlichkeit damals erregten und worüber man sich das Zwerchfell zerri ${ }^{90}$. Es wird im einzelnen noch weiter unten $\mathrm{zu}$

${ }^{85}$ Vgl. CHABOT, Synodicon Orientale (wie Anm. 4), 55, Z. 11. Der syr. Text spielt hier mit der doppelten Bedeutung von $\sigma \chi \tilde{\eta} \mu \alpha$ : Das Mönchs-"schema" gebe lediglich den Anschein von Frömmigkeit.

${ }^{86}$ Vgl. O. BraUn, Synodicon Orientale (wie Anm. 4), $67 \mathrm{f}$.

${ }^{87} \mathrm{Vgl}$. CHABOT, Synodicon Orientale (wie Anm. 4), 55, Z. 16-20: ...damit ibr (sc. der Mönche) Aufenthalt an einem zu ibnen passenden Ort sei. Städte und Ortschaften, in denen böhere Geistliche (kâhne), Bischöfe, Priester und Diakone, sind, dürfen sie nicht betreten, um (dort) zu wobnen, Streit zu verursachen und Verwirrung zwischen den Geistlichen und den Herden, zwischen den Meistern und den Scbülern zu stiften.

${ }^{88} \mathrm{Daß}$ der Klerus nunmehr verheiratet sein sollte, geht aus c. 3 hervor.

${ }^{89} \mathrm{Vgl}$. dazu auch die Ausführungen in Kap. 3.1.

${ }^{90}$ Vgl. Braun, Synodicon Orientale (wie Anm. 4), 69. Gerö, Barsauma (wie Anm. 2), $83 \mathrm{f}$, glaubt nicht, daß die Synoden von 484/486 per se antimonastisch ausgerichtet gewesen seien. Doch ist dies zu bezweifeln, wiewohl die Abschaffung der Klerikerenthaltsamkeit gewiß nicht das Werk eines einzelnen Mannes wie Barsauma war. Es ist bezeichnend, daß GERÖ gegenüber den monophysitischen Nachrichten hyperkritisch eingestellt ist, während er die der Nestorianer oft unkritisch übernimmt. Was sich konkret an historischer Realität hinter den Skandalgeschichten verbirgt, entzieht sich unserer Kenntnis. Derartige Vorkommnisse waren freilich Wasser auf die Mühlen all derer, die eine Änderung der bestehenden Rechtspraxis herbeiwünschten und die peinlichen Vorgänge noch künstlich aufbauschten. Doch wird man sich davor hüten, aus den genannten Einzelfällen voreilige Rückschlüsse auf den moralischen Zustand des persischen Klerus im allgemeinen zu ziehen. 
untersuchen sein, inwieweit tatsächlich äußere gesellschaftliche Faktoren ${ }^{91}$ an dem synodalen Entscheidungsprozeß maßgeblich beteiligt gewesen waren. Zunächst geht es den Synodenvätern innerkirchlich um eine deutliche Abgrenzung der nestorianischen Rechtspraxis gegenüber der rigiden monophysitischen und messalianischen Moral. Die Kanones des Rabbu$\mathrm{la}^{92}$ etwa sahen schwere Kirchenbußen für die klerikale Unkeuschheit vor, waren äußerst zurückhaltend bei der Dispensierung von einmal gegebenen Enthaltsamkeitsversprechen und regelten peinlich genau das Verhalten von zölibatären Priestern und Diakonen gegenüber Personen anderen Geschlechts.

Der überlange c. 3 der Synode von 486, der mühelos in mehrere Paragraphen geteilt werden könnte, regelt zunächst die Eheschließung von $\mathrm{Bi}$ schöfen, Priestern und Diakonen ${ }^{93}$ nach empfangener Weihe, die entgegen altkirchlicher Rechtspraxis ${ }^{94}$ nicht mehr ausgeschlossen wird. Die Zulassung von viri probati zur Weihe ${ }^{95}$ stellt in diesem Kontext ein nachgeordnetes Problem dar, obwohl sich hier schon erste Schwierigkeiten andeuten, geeignete Weihekandidaten zu finden. Den Diakonen wird ein ziemlich langer Textpassus eingeräumt, was sich durch den Umstand erklärt, daß die Enthaltsamkeitspflicht für Kleriker ab dem Diakonat galt, in

${ }^{91}$ Vgl. dazu ST. GERÖ, Die antiasketische Bewegung im persischen Christentum - Einfluß zoroastrischer Ethik?, in: OCA 221 (1983) 187-191, bestreitet jeglichen äußeren Einfluß auf die inneren Entwicklungen in der persischen Kirche.

${ }^{92}$ Vgl. c. II,2-4. 28f: BRUNS, Kanones (wie Anm. 84), 474f. 477. So war es den Priestern und Diakonen nicht gestattet, sich von Frauen bedienen zu lassen.

${ }^{93}$ Die Gedankenführung, vgl. Braun, Synodicon Orientale (wie Anm. 4), 69-72, erweckt einen ziemlich ungeordneten Eindruck, weshalb spätere Rechtsgelehrte sie stärker gestrafft und systematisiert haben, so die arab. Übersetzung der Acacius-Synode bei ASSEMANI, BOCV III/1,378-395, bes. 390f.

${ }^{94}$ Vgl. dazu ST. HEID, Zölibat in der frühen Kirche. Die Anfänge einer Enthaltsamkeitspflicht für Kleriker in Ost und West, Paderborn ${ }^{3} 2003$, zum syr. Raum vgl. bes. die Ausführungen zur Didaskalie, $83 \mathrm{f}$.

${ }^{95}$ Auch fügen wir folgendes diesem Kanon binzu, daß von nun an in Zukunft kein Bischof jemandem aus seiner Stadt oder den ibm unterstebenden Dörfern die Hand zum Diakonat auflegen darf, obne zuvor untersucht zu baben, ob der Kandidat über einen guten, der Handauflegung würdigen Lebenswandel verfügt, und damit verbunden, eine gesetzmäßige Ehe mit Kinderzeugung fübrt, damit aus der Kirche Christi aller Hochmut und die Zurschaustellung irriger Lebren derjenigen ausradiert werden, die Ebe und Kinderzeugung böse nennen, obgleich sie selbst ibre Begierde in Ehebruch, Hurerei und schimpflichen Taten befriedigen (СНАВОТ, Synodicon Orientale [wie Anm. 4], 57,20-27). Daß Ehe und Kinderzeugung "böse" (bî̌sâ) genannt werden, könnte auf einen manichäistischen Hintergrund hindeuten. 
der verschärften syrischen Fassung der nizänischen Kanones von $410^{96}$ war sie sogar auf die Subdiakone ausgedehnt worden. Mit der bisherigen Rechtspraxis ${ }^{97}$ soll nun gebrochen werden: Auch den Diakonen, die bereits die Handauflegung des Diakonates empfangen baben, und zwar einem jeden einzelnen von ibnen, ist es erlaubt, sich mit einer einzigen Frau in ordentlicher und gesetzmäßiger Ebe zu verbinden und sich von der alten Gewobnheit (sic!), welche durch die Laxbeit der Unkeuschen von den Außenstebenden geschmäbt und gelästert wird, loszusagen. Bezüglich derer, die eben erst zur Handauflegung des Diakonates kommen, soll über ibr anderweitiges Verbalten wie auch ibre gesetzmäßige Ehe nachgeforscht werden. Wenn sie ordentlich verbeiratet sind, sollen sie die Handauflegung des Diakonates erbalten, um die apostolische Lebre zu erfüllen, die besagt: "Die Diakone seien Gatten einer einzigen Frau, die ibren Kindern und Häusern gut vorsteben" $(1 \operatorname{Tim} 3,12)^{98}$.

Die Väter betreiben vornehmlich Imagepflege, wenn sie aus Sorge um das gesellschaftliche Ansehen des geistlichen Standes von der traditionellen Enthaltsamkeitspraxis abrücken. Sie nehmen bewußt den Bruch mit einer alten Tradition ("yâdâ 'atiqâ) ) $^{99}$ in Kauf, um den "Außenstehenden" zu gefallen. Es würde freilich zu weit führen, an dieser Stelle im einzelnen zu untersuchen, inwieweit sich die Exegese der Pastoralbriefe (1 Tim 3) der Deutung des unius uxoris vir bei Theodor von Mopsuestia ${ }^{100}$ verdankt. Es liegt zweifelsfrei eine vollkommene Abhängigkeit vor, was bei der Sonderstellung des Bischofs von Mopsuestia innerhalb der ostsyrischen

${ }^{96}$ Vgl. dazu CHABOT, Synodicon Orientale (wie Anm. 4), 24, Z. 6-12; BRAUN, Synodicon Orientale (wie Anm. 4), 70, Anm. 2, verweist auf den greisen Diakon Aitillaha, der das blutige Martyrium einer Sünde gegen die Keuschheit vorzog.

${ }^{97}$ Die Rechtspraxis der Klerikerenthaltsamkeit im syrisch-mesopotamischen Raum unterschied sich nicht wesentlich von derjenigen der Reichskirche des vierten Jahrhunderts, vgl. HEID (wie Anm. 93), 131-182, war vielmehr, wie das Beispiel Rabbula zeigt, in manchen Punkten noch rigider. Es stimmt daher nicht, wenn GERÖ, Barsauma (wie Anm. 2), 81, Anm. 15, behauptet, daß es keine Evidenz für die traditionelle Praxis der klerikalen Enthaltsamkeit gebe. Hier sei nur auf die Chronik von Seert (PO IV,237f) verwiesen, ganz abgesehen von der zuvor erwähnten Synode von 410 .

${ }^{98}$ CHABOT, Synodicon Orientale (wie Anm. 4), 57, Z. 7-16.

${ }^{99}$ Der syr. Terminus zeigt an, daß die Klerikerenthaltsamkeit im Mesopotamien des fünften Jahrhunderts längst Tradition war und als Ideal hochgehalten wurde, auch wenn viele einzelne Priester und Diakone versagten.

${ }^{100}$ Vgl. dazu HEID (wie Anm. 93), 145-150. 
Literatur ${ }^{101}$ kaum verwundern kann. Wie Theodor fragen auch die Synodenväter bei der "einen Frau" der Kleriker nicht danach, in der wievielten Ehe ein Weihebewerber bzw. ein Geweihter lebt. Die zweite oder dritte Ehe ist nach c. 3 der Synode des Aqâq ebenso gut den Laien gestattet wie den geweihten Amtsträgern. Die nach weltlichem persischen Recht erlaubte Bigamie war keinem Christgläubigen, erst recht nicht dem Kleriker, gestattet. Ausgeschlossen werden sollte lediglich die bei den Orientalen so beliebte Vielweiberei, aber auch das illegitime Konkubinat der Kleriker. Generell gilt die Maxime: Wenn ein bisher unverbeirateter Priester ordnungsgemäß beiraten und rechtmäßig Kinder zeugen will, oder wenn jemandem seine erste Frau verstarb und er eine zweite nebmen und er der zweiten wie der ersten die ebeliche Treue balten will, dann darf ibn sein Bischof nicht von seinem Willen abbalten ${ }^{102}$.

Es folgen Strafbestimmungen für diejenigen, die (in manichäistischer Manier?) Ehe und Kinderzeugung herabsetzen, und allgemeine Warnungen vor den Umtrieben der Mönche im Betrügerbabit ${ }^{103}$. Freilich geben sich die Synodenväter keinen Illusionen hin: Auch die Priesterehe kann scheitern; der verheiratete, unkeusche Priester ${ }^{104}$ ist daher auf der Stelle zu suspendieren. Im Hinblick auf die Ehe gelten für die Priester die gleichen Anforderungen wie für die Laien ${ }^{105}$. Vor und nach der Priesterweihe bleibt die Ehe jedoch gestattet ${ }^{106}$. Völlig unklar hingegen sind die Synodenbestimmungen hinsichtlich der wiederverheirateten, geschiedenen

${ }^{101}$ BAUMSTARK, Geschichte (wie Anm. 27), 102-104. Es ist unnötig, nach einer syr. Übersetzung der griech. Pauluskommentare zu forschen, da die in Edessa geschulten Bischöfe ohnehin des Griechischen mächtig waren und die Werke des "großen Interpreten" im Original lesen konnten.

${ }^{102}$ CHABOT, Synodicon Orientale (wie Anm. 4), 58, Z. 10-14.

${ }^{103}$ Ebd., 58, Z. 23: eskîmâ zîpânâ.

${ }^{104}$ Ebd., 58, Z. 6-10: Wenn jemand eine rechtmäßige Ehe eingebt und außerbalb des Verkebrs mit einer einzigen Ehefrau es wagen sollte, noch weitere zu gebrauchen... dann soll er gleichfalls der kirchlichen Gemeinschaft und dem priesterlichen Rang fremd sein. Es geht aus dem Zusammenhang nicht hervor, ob dem verheirateten, ehebrecherischen Priester noch eine Bußmöglichkeit offen steht. Der unverheiratete Priester, der im Konkubinat angetroffen wird, wird suspendiert, hat aber noch die Chance, durch Buße in Amt und Würden zurückzukehren, vgl. BRAUN, Synodicon Orientale (wie Anm. 4), 72.

${ }^{105} \mathrm{Da}$ der primäre Zweck der Ehe in der Zeugung von Nachkommenschaft besteht, ist die absichtliche Unfruchtbarmachung nicht gestattet.

${ }^{106}$ СНАBОT, Synodicon Orientale (wie Anm. 4), 58, Z. 14-16: Die ordentliche Ebe und Kinderzeugung ist sowobl vor als auch nach der Priesterweibe gut und gottgefällig. 
Priester ${ }^{107}$; doch auch in diesem Punkte geben sich die Väter sehr großzügig: sie dürfen heiraten, sooft sie nur wollen. Gerechnet wird ferner mit der Möglichkeit, daß nicht alle Priester ihre frei gewählte Ehelosigkeit aufgeben $^{108}$, sie dürfen allerdings im Kirchendienst verbleiben, sofern sie nicht im illegitimen Konkubinat leben. Doch neigen die Synodenväter eindeutig dazu, den unverheirateten Klerus in die Klöster oder Einsiedeleien zu verbannen. Mit diesem Schritt hat sich die persische Kirche in disziplinarischer Hinsicht sowohl von der Reichskirche als auch ganz besonders von ihrer monophysitischen Konkurrenz getrennt.

\subsection{Die Synode des Babai (497)}

Unter dem Katholikat des nach monophysitischen wie nestorianischen Zeugnissen verheirateten Patriarchen $\mathrm{Babai}^{109}$ setzte die persische Kirche den unter Aqâq eingeschlagenen kirchenpolitischen Kurs fort. Babai bar Hormizd war bei seiner Wahl zum Katholikos kein unbeschriebenes Blatt. Als Sohn des Hormizd, des Sekretärs des Marzban Zabergan vom "Aramä-

${ }^{107}$ Die komplizierte Textgeschichte verbirgt einige ernsthafte pastorale Probleme, vgl. ebd. 58, Z. 16-19: Die Ehe mit einer einzigen Frau, auch wenn ein Wechsel stattfand durch die Gewalt des Todes (?) oder andere zwingende Ursachen, die sich in der Welt ereignen, wird dem Bruder zugestanden, selbst wenn er ein weiteres Mal durch aufeinanderfolgende Kopulation in Versuchung gerät... Der syr. Text ist in Unordnung geraten. Auch die geraffte arab. Zusammenfassung bei ASSEMANI, BOCV III/1,390f, bietet kaum Hilfe bei der Rekonstruktion des ursprünglich Gemeinten. Den späteren Kanonisten geht es vor allem um die Interpretation des Digamieverbots. Die syr. Mss lesen d-râmûtâ (Hochmut), was keinen Sinn ergibt (diplographisches $d$, Verschreibung von $r$ statt $d$ ?). Chabot konjiziert $d$-mautâ (Tod), läßt aber die "Versuchung" unübersetzt (Lesefehler: statt mtns' mtnsb gelesen?), (ebd., 58; 305). BRAUN, Synodicon Orientale (wie Anm. 4), 72, Anm. 1, verbessert in zânyûtâ (Unzucht), legt also die Unzuchtsklausel zugrunde. Chabot nennt Unzucht oder längere Abwesenheit aufgrund von Gefangenschaft als triftige Scheidungsgründe (ebd., 305, Anm. 3 ).

${ }^{108}$ Ebd., 57, Z. 31 bis 58, Z. 2: Indem wir also lebren: Wer nach eigenem Willen die Enthaltung von der Ebe erwäblt, der harre aus an einsamer Wobnstatt obne Zerstreuung, keusch und tapfer, und wer, obwobl im Kirchendienst stebend, es erwählt, Christus in Keuschbeit und Entsagung alles Irdischen zu gefallen, (möge es tun)... .

${ }^{109}$ Nach der Chronik von Seert (PO VII/2,128-130) soll Babai schon sehr betagt gewesen sein und gleichsam in der nachfamiliären Phase mit großem Widerwillen zum Katholikat gedrängt worden sein. Salomon von Basra merkt in seinem exegetischen Sammelwerk Liber Apis, cap. 51, (lat. Übers. bei J. M. SCHÖNFELDER, Salomonis ep. Bassorensis liber apis, Bambergae 1866, 84), nur von zwei Katholikoi, nämlich Babai und Schîlâ, an, daß sie geheiratet hätten. Doch hat Babai, nach der Chronik von Seert "reich an Jahren", nicht wie Barsauma erst nach der Weihe geheiratet und Kinder gezeugt. 
erland" (mittleres Mesopotamien mit Zentrum Seleukia-Ktesiphon) ${ }^{110}$, und außerdem noch mit dem persischen Hofastrologen Moses verwandt, galt er den Behörden als politisch unverdächtig. Als Theologe war er Schüler des Mari von Tahal und strenger Dyophysit, welcher nach Angabe des Simeon von Beth-Arscham ${ }^{111}$ die Häresie des Diodor von Tarsus und Pauls von Samosata erneuert habe. Vom Vater hatte Babai das nötige diplomatische Fingerspitzengefühl geerbt, das ihm bei seinem schwierigen Unterfangen half, die persische Kirche aus den Thronwirren um den gestürzten Großkönig Qawad herauszuhalten. Im Gegensatz zum Vorgänger Peroz, der als Christenverfolger in der syrischen Geschichtsschreibung zu traurigem Ruhm gelangt ist, weiß die Chronik von Seert viel Ehrenvolles über Qawad ${ }^{112} \mathrm{zu}$ berichten, sie rühmt seine persönliche Bescheidenheit und Aufgeschlossenheit für religiöse Fragen, seine Toleranz gegenüber den Christen und seine staatsmännische Weitsicht, obwohl sie die Schattenseiten eines der größten Herrschers der persischen Geschichte keineswegs verschweigt. Qawad (488-496; 498-531) konnte sich gegen seinen Bruder Balasch ${ }^{113}$ nur mit Hilfe der verbündeten Hephthaliten, zu denen er seit seiner Gefangenschaft ein enges Verhältnis hatte, behaupten. Er war zwar äußerlich Zoroastrier, bekannte sich aber persönlich zur kommunistisch-schwärmerischen Sekte der Mazdakiten ${ }^{114}$, förderte den Städtebau und die Landwirtschaft, ließ gleichzeitig Kirchen und öffentliche Lusttempel errichten.

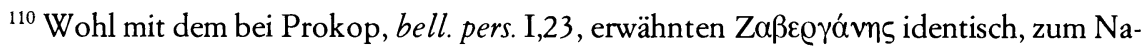
men Zabargân, arab. Zibriqân vgl. auch NöLDEKE (wie Anm. 33), 252.

${ }^{111}$ Ferner bannen wir Mari von Beth-Tabal, den Lebrmeister des Katholikos Babai, denn in den Tagen des Babai trat ebenjener Mari auf, der die Häresie derer vom Hause des Paul von Samosata und des Diodor im Aramäerland lebrte. Bei ibm nabm auch Unterricht der Katholikos Babai bar Hormizd, welcher der Sekretär des Zabargan aus dem Aramäerland war (ASSEMANI, BOCV I,358). Daß Babai in theologicis gänzlich unbedarft gewesen sein soll, ja nicht einmal lesen und schreiben konnte, wie gelegentlich behauptet wird (PO VII/2129, Anm. 2), ist frei erfunden und entspringt reiner Polemik.

${ }^{112}$ Vgl. Chronik von Seert (PO VII/2,124f); zur Regierung des nach Chosrau vielleicht bedeutendsten persischen Monarchen vgl. auch SCHIPpMANN, Grundzüge (wie Anm. 25), 45-52; NÖLDEKE (wie Anm. 33), 135-147; Sondergut liegt im XVII. Kapitel vor, in dem der Chronist (PO VII/2,132f) von der Schonung der christlichen Bevölkerung durch Qawad nach einer Vision handelt.

${ }^{113}$ NÖLDEKE (wie Anm. 33), 133f. Die Chronik von Seert nennt einen gewissen Milâs als Gegenspieler des Qabâd, was aber wohl eine Verschreibung für Balasch sein dürfte. Zum Namen Qawad (arab. Qabâd) vgl. ebd., 135, Anm. 1.

${ }^{114}$ Ebd., 141-144. 455-467; zum sozialen Hintergrund der Affäre vgl. N. PIGULEvSKAJA, Les villes de l'état iranien aux époques parthe et sassanide, Paris 1963, 196-230; A. CHRISTENSEN, Le règne du roi Kawâdh I. et le communisme mazdakite, Kopenhagen 1925. 
Qawads innenpolitischer Kurs stieß auf den Widerstand der alten Eliten, besonders aber der Priesterkaste der Magier, die den Usurpator Zamasp ${ }^{15}$ an die Macht putschten. Babai deckte damals dank seiner guten Beziehungen zum Hof die geheime Flucht ${ }^{116}$ des entthronten Großkönigs, ohne sein entspanntes Verhältnis zum regierenden Herrscher zu gefährden. So gelang es dem Katholikos, auf Weisung ( $\sigma \alpha ́ v \varrho \alpha$, v. lat. [epistula] sacra, s.u.) des Großkönigs Zamasp Ende 497 zweiunddreißig Bischöfe ${ }^{117}$ zu einer Synode in Seleukia-Ktesiphon zu versammeln. Sein erklärtes Ziel war es, nach dem Ableben des aufsässigen Barsauma, der dem Vorgänger Aqâq solche Schwierigkeiten gemacht hatte, einen Schlußstrich unter die leidige Affäre zu ziehen und die am Streit beteiligten Parteien miteinander zu versöhnen ${ }^{118}$. Neben einer Terminfrage und der Disziplinierung aufsässiger Suffragane, die uns an dieser Stelle nicht zu beschäftigen braucht ${ }^{119}$, werden die bereits geltenden Bestimmungen hinsichtlich der Klerikerenthaltsamkeit erneut bekräftigt: Wir alle baben uns versammelt in guter Absicht und Liebe zur Ebre und zum Friedensgruß unseres ebrwürdigen Vaters, des Katholikos Mar Babai, nachdem wir in die Städte Seleukia-Ktesiphon gekommen waren und dem Friedvollen und Freundlichen in der Liebe Christi unsere Aufwartung gemacht batten. Auch er hat uns gutwillig und liebevoll aufgenommen wie Brüder und als Glieder desselben väterlichen Herrschertums und bat uns

${ }^{115}$ Vgl. Chronik von Seert (PO VII/2,127f); NÖLDEKE (wie Anm. 33), 142.

${ }^{116}$ Dramatisch geschildert in der Chronik von Seert (PO VII/2,127f), mit leichten Abweichungen bei NöLDEKE (wie Anm. 33), 143f. Demnach wurde Qawad im Wäschesack von seiner Schwester aus dem Gefängnis herausgeschmuggelt. Der Chronist hebt eigens hervor, daß Christen (Kaufleute oder Mönche?) dem König bei seiner Reise ins "Türkenland" zu Diensten waren. Zu den romanhaften Ausschmückungen der Flucht vgl. auch CHRISTENSEN, Iran (wie Anm. 26), 349, Anm. 2.

${ }^{117}$ Vgl. Chronik von Seert (PO VII/2,129); es liegen drei, leicht divergierende Bischofslisten vor, die vom Kopisten nachträglich in die Handschrift eingefügt wurden, vgl. dazu CHABOT, Synodicon Orientale (wie Anm. 4), 62-68. 310-317. 620; BRAun, Synodicon Orientale (wie Anm. 4), 83-92; zur Teilnehmerliste vgl. bes. die Diskussion ebd., 92, Anm. 3.

${ }^{118}$ Vgl. ebd., 88. Demnach wäre es wegen Barsauma noch in den ersten Regierungsjahren des Zamasp zu Streit und Zerwürfnis im Episkopat gekommen, vgl. dazu GERÖ, Barsauma (wie Anm. 2), 53f. Die Synode verfügt daher die Aufhebung aller unrechtmäßigen Bannflüche und läßt die gehässige Korrespondenz der Bischöfe einäschern.

${ }^{119}$ Provinzsynoden sollen gemäß altkirchlichem Brauch zweimal im Jahr stattfinden; die Plenarsynode von nun an nur noch alle vier Jahre und zwar im ersten Tischri (Herbst), sofern nicht besondere Umstände etwas anderes erheischen. Weitere Ausführungen der Väter, vgl. BRAUN, Synodicon Orientale (wie Anm. 4), 89f, betreffen sehr konkrete Maßnahmen gegen den Metropoliten Jazdâd von Rew Ardaschir in der Persis, der die kirchliche communio mit dem regierenden Katholikos verweigerte. 
jene sacra gezeigt, welche ihm vom friedliebenden, gutwilligen Großkönig Zamasp geschickt worden war, daß die ibm unterstebenden Bischöfe sich versammeln und eine Korrektur (turâsâ) binsichtlich der rechtmäßigen Ehe und Kinderzeugung für alle Bundessöbne (Kleriker) an den verschiedenen Orten durchfübren sollten. Und wir alle, deren Namen oben geschrieben steben, nebmen einmütigen und gleichfalls mit den Gesetzen Cbristi übereinstimmenden Sinnes die bezüglich der Ebe und Kinderzeugung uns und unsere Herden geziemenden Korrekturen vor und geben die Erlaubnis (mapsânûtâ), daß jeder, vom Patriarchen bis zum Geringsten im Bunde, öffentlich eine reine Ebe mit einer einzigen Frau, mit der er Kinder zeugen darf, schließe und davon Gebrauch mache. Dabei stimmen wir nur in diesem einzigen Punkte jener Synode im Lande Huzistan bei, welche im Jabre 27 des Großkönigs Peroz in der Stadt Beth-Lapat stattfand, und jenem Schreiben, das im zweiten Jabre des Balasch in Beth-'Adrai in den Tagen des Aqâq seinen Anfang nabm und im Aramäerland vollendet wurde... ${ }^{120}$.

Gerö $^{121}$ hat auf das erstaunliche Faktum verwiesen, daß es eine großkönigliche (epistula) sacra war, welche die Aufhebung der Klerikerenthaltsamkeit von den Synodenvätern forderte. Zwar wird man nicht behaupten können, daß Barsauma 484 in Beth-Lapat ebenfalls auf einen schriftlichen Befehl des persischen Großkönigs hin tätig geworden sei, doch ist auch nicht mit Sicherheit auszuschließen, daß er durchaus in Peroz' Sinne gehandelt hat. Nicht zu bestreiten ist aufgrund der Aktenlage, daß Barsauma 484 einen Vorstoß zur Aufhebung der Klerikerenthaltsamkeit unternommen hatte, der allerdings erst auf der Provinzsynode von Beth-'Adrai Wirkungen zeigte und schließlich 486 auf der Plenarsynode des Aqâq seine endgültige Bestätigung fand. Insofern reiht sich die Synode von 497, was die Klerikerdisziplin anbelangt, in den Reigen der Vorgängersynoden ein, markiert aber, wie noch im einzelnen zu zeigen sein wird, einen radikalen Bruch mit den asketischen Idealen früherer Jahrhunderte ${ }^{122}$.

Exkurs: Schauplatz Armenien

Der armenische Historiker Moses von Choren, der gemeinhin als Begründer einer autochtonen Historiographie gilt, überliefert in seiner "Geschichte

\footnotetext{
${ }^{120}$ CHABOT, Synodicon Orientale (wie Anm. 4), 63,5-21.

${ }^{121} \mathrm{Vgl}$. GERÖ, Barsauma (wie Anm. 2), 86.

${ }^{122}$ Dies kann selbst Gerö nicht bestreiten (ebd., 87).
} 
der Armenier"123 (bist. III,64) die aufsehenerregende Begebenheit von einem syrischen Gegenpatriarchen namens Brkischo oder Brichischo (von Jesus gesegnet), der vom persischen Großkönig Bahram V. (420-438) eingesetzt, zusammen mit liederlichen, beweibten Bischofskumpanen eine ganze Kirchenprovinz der Armenier ausgeplündert habe: Aber es dauerte gerade nicht einmal mebr als ein Jabr, als Surmak von ebendenselben Satrapen vom Thron vertrieben wurde. Daraufbin erlangte er vom persischen Herrscher die eigene Provinz Bznunik als Bistum für den Familienbesitz. Unsere Fürsten jedoch verlangten von Vram (Bahram) einen anderen auf dem Thron, und er gab ibnen einen Syrer, Brkischo. Dieser kam mit nichtswürdigen Kumpanen, welche zudem ibre Frauen als Haushälterinnen (tnkalowč) mit sich fübrten. Drei Jabre lang fübrte er ein zügelloses, ausschweifendes Leben, indem er die verwaisten Diözesen ausplünderte. Als die Fürsten ibn nicht mebr ertragen konnten, erbaten sie erneut von Vram, ibn auszuwechseln und ibnen jemanden mit den gleichen religiösen Sitten zu geben. Die Hälfte von ibnen forderte Sabak den Großen ${ }^{124}$.

Folgt man Moses' Chronologie, so wären diese skandalösen Vorkommnisse auf das Jahr 429 nach dem Untergang des armenischen Königtums zu datieren; O. Braun ${ }^{125}$ nahm dies seinerzeit zum Anlaß, um auf die generell laxe Observanz der Syrer in puncto Klerikerenthaltsamkeit zu verweisen. Doch sind gewisse Zweifel angebracht. Zum einen tendiert die heutige Forschung ${ }^{126}$ eher zu einer Spätdatierung (8. Jh.) des unter dem Namen "Moses von Choren" tradierten Geschichtswerkes, was die Verarbeitung älterer Überlieferung keinesfalls auszuschließen braucht. Selbst wenn man also Teile der "Geschichte der Armenier" noch auf das späte fünfte Jahrhundert datiert, so ist auf jeden Fall mit späteren Bearbeitungen dieses Stoffes zu rechnen. Zum anderen ist für die hier zu untersuchenden Vorgänge noch eine weitere Belegstelle aus der armenischen Literatur, die wahrscheinlich das Vorbild für Moses bildete, heranzuziehen. Sie findet sich in der "Ge-

${ }^{123}$ Krit. Ausgabe: M. AbeŁEAN - S. Yarutiunean (Hg.), Movsisi Khorenatswoy Patmutiun Hayots, Tiflis 1913, (repr. New York 1981); engl. Übers. bei R. W. THOMSON, Moses Khorenats'i . History of the Armenians, Cambridge (MA) ${ }^{2} 1982$.

${ }^{124}$ Moses Chor., hist. III,64: (ABEŁEAN - YARUTIUNEAN 349,10-19)

${ }^{125}$ Vgl. dazu BRAUN, Synodicon Orientale (wie Anm. 4), 61, Anm. 1.

${ }^{126}$ Vgl. dazu die Einleitungsfragen bei THOMSON, Moses Khorenats'i (wie Anm. 123), 1 61. Moses Chor., hist. III,62 erweckt den Eindruck einer Zeitgenossenschaft mit Sahak und Mesrop, doch verraten ihn einige Anachronismen als späteren Redaktor und Kompilator. 
schichte der Armenier" des Lazarus von Parpi ${ }^{127}$, eines Autors aus dem ausgehenden fünften Jahrhunderts. Dieser behandelt in hist. 15 zunächst die Einsetzung des Katholikos Surmak und seine spätere Absetzung durch armenische Fürsten. Um die Ordnung im Lande wiederherzustellen, habe der persische Großkönig Vřam, gemeint ist Bahrâm V. (420-438), zum ersten Male einen Marzpan (Markgrafen) in der aufsässigen Provinz installiert. Lazarus fährt fort:

Daraufhin verlangten die Satrapen der Armenier vom königlichen Hofe für sich selbst einen Katbolikos, und König Vram gab ibnen einen gewissen Brkischo mit Namen, einen Mann vom Stamme der Syrer. Dieser kam ins Armenierland zusammen mit seinen Provinzgenossen, welche ibre losen Sitten lebten, indem sie ibrer Landessitte gemäß ibre Matronen aus Assyrien (Asorestan) mitbrachten. Sie lebten nicht in Übereinstimmung mit der beiligen, makellosen. Ordnung, welche in der gesamten armenischen Kirche durch den beiligen Helden Gregor festgelegt und vorgeschrieben worden war. Da wurden die größten der armenischen Stammesoberbäupter, die vornebmen Adeligen und auch der gesamte Volkshaufen, ungebalten wegen der Unsitten jener Leute, welche mit dem Katholikos Brkischo gekommen waren. Sie stimmten nicht überein mit Kanon und Lebre der engelgleichen Anordnungen des beiligen Helden Gregors, mit denen er jedermann in der Himmelsbürgerschaft unterwiesen, genäbrt und festgegründet bat ${ }^{128}$.

Brkischo wird schließlich durch eine Adelsrevolte des Amtes enthoben $^{129}$. Die Stammesoberhäupter setzen den persischen Großkönig von den Vorgängen in Kenntnis und bitten erneut um die Entsendung eines geistlichen Würdenträgers, der diesmal jedoch die religiösen Traditionen des armenischen Volkes respektieren soll. Dem Wunsch wird entsprochen, doch bringt der neuinstallierte Katholikos Samuel sehr zum Verdruß des armenischen Adels keine Besserung der allgemeinen kirchlichen Lage. Im Gegenteil, er treibt es noch schlimmer als sein Vorgänger Brkischo, kann jedoch

${ }^{127}$ Krit. Ausgabe bei: G. TER-MEKERTTSChIAN - S. MALKhaSIAn, Łazar P'arpets'i. History of the Armenians and the Letter to Vahan Mamikonean, Tiflis 1904, (repr. New York 1981); engl. Übers.: R. W. THOMSON, The History of Łazar P'arpets'i, Atlanta 1985. Zur Frage der literarischen Abhängigkeit des Moses von Lazarus vgl. ebd., 5.

${ }^{128}$ Ter-MeKerTTSCHIAN - MALKHASIAN, Łazar P'arpets'i (wie Anm. 127), 26,5-16. Moses von Choren erwähnt in diesem Zusammenhang bezeichnenderweise nicht, daß das Mitführen von Frauen als Haushälterinnen (sic!) nach syrischer Landessitte geschehen sei. Möglicherweise ist dies als Indiz für den Umstand zu werten, daß die nestorianischen Katholikoi zu seiner Zeit (8./9. Jh.?) wieder zur alten Praxis zurückgekehrt waren, s. u. den Ausblick.

${ }^{129} \mathrm{Vgl}$. ThOMSON, History of Łazar P'arpets'i (wie Anm. 127), $61 \mathrm{f}$. 
aufgrund seines plötzlichen Ablebens keinen dauerhaften Schaden in der armenischen Kirche anrichten.

Lazarus' schroffe antisyrische, antipersische Polemik kennt verschiedene Ursachen. Sein Patriotismus ${ }^{130}$ wurde durch den endgültigen Verlust des armenischen Königtums (428), den Freiheitskriegen unter Vardan (450/451) und dessen Neffen Vahan dem Mamikonier (482-484) entfacht. Lazarus schreibt aus der Perspektive eines mit dem Herrscherhaus der Mamikonier eng befreundeten Historikers, für den das Christentum in Gestalt des als Heiligen verehrten Gregors des Erleuchters die maßgebliche Religion des armenischen Volkes ${ }^{131}$ darstellt. Er sieht sein Volk durch die Perser - er nennt sie eine "gottlose Rasse" 132 - politisch und religiös geknechtet. Nicht nur die zoroastrischen Feuerpriester bilden eine reale Gefahr für die religiöse Identität des armenischen Volkes, sondern auch die abweichende Disziplin ${ }^{133}$ der persischen "Nestorianer", welche die Protektion des Großkönigs genießen. Eine konfessionelle Standortbestimmung des Lazarus von Parpi erscheint allerdings schwer möglich; seine vielfach bezeugte gräkophile Einstellung läßt eine Zustimmung zum Chalcedonense ${ }^{134}$ nicht völlig unmöglich erscheinen. Träfe eine solche Vermutung zu, dann hätte sich unser Autor angesichts der schleichenden "Monophysitisierung" Armeniens nach Zenons Henotikon (482) freiwillig ins kirchenpolitische Abseits begeben. Der Konflikt mit dem späteren Katholikos Babgen, der auf der Synode von Dwin (505/06) offen für die Annahme des Henotikon plädierte, hätte so eine plausible Erklärung gefunden. Die Geschichte der armenischen Reaktionen auf das Chalcedonense ist von N. Garsoïan ${ }^{135}$ bereits anderweitig erschöpfend erörtert worden. Lazarus' Äußerungen zu den inhaltlichen Aspekten der persischen Bedrohung sind spärlich, doch setzt er offenkundig eine Differenz zum ostsyrischen Christentum nicht nur in der Lehre, sondern auch in der Klerikerdisziplin ${ }^{136}$ voraus. Der Priester aus Parpi war

${ }^{130} \mathrm{Vgl}$. dazu die Einleitung ebd., 1-31.

${ }^{131}$ Vgl. ebd., 28.

${ }^{132}$ Vgl. ebd., 60.

${ }^{133}$ Daher auch der Appell der Fürsten an den Großkönig, einen Bischof, der sich an die traditionelle Ordnung der armenischen Kirche hält, zu entsenden, vgl. ebd., $61 \mathrm{f}$.

${ }^{134}$ Vgl. ebd., 29-31.

${ }^{135}$ Vgl. N. GaRSOÏAN, L'église arménienne et le grand schisme d'orient, Louvain 1999; zu Barsauma vgl. den Index, 588.

${ }^{136}$ Lazarus spricht von den loyc krawniwk' der Syrer, was nicht nur die losen Sitten, sondern auch die pervertierte Religion meinen kann. Nicht zufällig ist weiter unten von der engelgleichen Ordnung (hreštakakrawn kardaworow' eamb) die Rede, die der Erleuchter in Armenien etabliert habe. Darunter ist nicht nur die himmlische Lehre zu verstehen, sondern auch 
nämlich ein strenger Asket, der unter Anleitung des Eremiten Moses mehrere harte Winter in einer Höhle der Provinz Siunik ${ }^{137}$ zugebracht und einen hohen Grad an Abtötung erlangt hatte. Daher wird seine ablehnende Haltung gegenüber den "losen Sitten" der Syrer nur allzu verständlich. Die Praxis, die eigenen Syneisakten (armen. tantikin) ${ }^{138}$ aus "Asorestan" ${ }^{139}$, d. h. aus Mesopotamien, mitzubringen, widersprach eindeutig den kanonistischen Bestimmungen der Armenier ${ }^{140}$. Wenn Lazarus nun sagt, das Mitführen von Syneisakten sei syrische Landessitte, so ist dies mehr als pure Polemik, kann sich aber gleichwohl schwerlich auf die Situation um 429 beziehen, da zu dieser Zeit in der persischen Kirche - zumindest offiziell - noch die Kanones von 410 galten, die in ihren strengen Bestimmungen den armenischen Verordnungen der Synode von Schahapivan (444 oder 447$)^{141}$ in nichts nachstanden. Die Vorgänge, die Lazarus hier beschreibt, spiegeln also eher die Situation der persischen Kirche nach (484) 486 wider, als die Klerikerenthaltsamkeit bereits offiziell aufgehoben worden war. Kann man bei Lazarus messalianistische Tendenzen ${ }^{142}$ nicht gänzlich verleugnen, so käme noch ein weiteres dogmatisches Argument gegen die disziplinären Neuerungen der Syrer aus Sicht der Armenier hinzu. Aqâqs Gegnerschaft zu den Messalianern ist sattsam bekannt, und dieser Umstand dürfte ihn in den streng

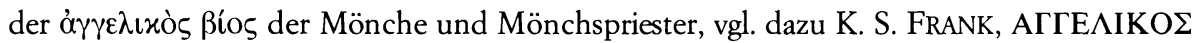
$\mathrm{BIO} \Sigma$. Begriffsanalytische und begriffsgeschichtliche Untersuchung zum "engelgleichen Leben” im frühen Mönchtum, Münster 1964.

${ }^{137}$ Vgl. zu diesem Teil der Biographie auch Thomson, History of Łazar P'arpets'i (wie Anm. 127), 6.

${ }^{138}$ Vgl. zu diesem Terminus auch ebd., 61, Anm.4.

${ }^{139}$ Gemeint ist das mesopotamische Kernland nördlich von Seleukia-Ktesiphon, das Land um Assur.

${ }^{140}$ Es kann hier keine Geschichte des Zölibats in der armenischen Kirche geboten werden. Noch immer lesenswert, wenngleich in einigen Einzelheiten überholt, sind die Ausführungen von S. WEBER, Die katholische Kirche in Armenien, ihre Begründung und Entwicklung vor der Trennung, Freiburg 1903, Index: Zölibat. Für das gesamte vierte Jahrhundert zieht Weber das Fazit: "Für den Bischof scheint also das Verbot der Ehe bestanden zu haben, dagegen hinderte eine vorhergehende Ehe die Erhebung nicht" (ebd., 345). Problematisch erschien den Armeniern lediglich die Heirat nach der empfangenen Weihe. Von den verheirateten höheren Geistlichen wurde nämlich erwartet, daß sie nach ihrer Erhebung nicht mehr mit ihren Frauen zusammenlebten. Sehr instruktiv sind in diesem Zusammenhang die Ausführungen des Faustus, hist. III,5; (engl. Übersetzung bei N. GARSOÏAN, The Epic Histories attributed to Pawstos Buzand, Cambridge (MA) 1989, 70 f.

${ }^{141}$ Gleich die ersten beiden Kanones befassen sich mit der Unkeuschheit der Kleriker, vgl. dazu THOMSON, History of Łazar P'arpets'i (wie Anm. 127), 30.

${ }^{142}$ Zur "Häresie" des Lazarus vgl. ebd., $29 f$. 
asketischen Zirkeln Armeniens nicht beliebter gemacht haben. Jedenfalls weiß Lazarus von Widerständen im armenischen Klerus gegen die persischen "Reformen" ${ }^{143}$ zu berichten. Zwar bestand bei aller Hochschätzung der Jungfräulichkeit, welche für Klosterinsassen und Eremiten ehernes Gesetz war, die Priesterehe in der armenischen Kirche des vierten und fünften Jahrhunderts ${ }^{144}$ fort, doch finden wir bei Faustus ${ }^{145}$ wie auch bei Lazarus die Tendenz, in ihren Lebensbeschreibungen der Katholikoi das asketische Moment stärker zu betonen. N. Garsoïan ${ }^{146}$ erblickt darin ein gegen die Zoroastrier gerichtetes Motiv; mit gleichem Recht könnte man auch von einer beginnenden Konfessionalisierung des armenischen Christentums in Abgrenzung zum persischen sprechen. Vollkommene Enthaltsamkeit war angesichts der engen Verquickung von dynastischen und geistlichen Interessen im armenischen Klerus ohnehin kaum möglich ${ }^{147}$. Doch hakt gerade an diesem Punkt Lazarus' Kritik ${ }^{148}$ am verweltlichten armenischen Kirchensystem

${ }^{143}$ Vgl. ebd., 28. 62. Nachdem das nationale Königtum erloschen ist, kommt noch die geistige Knechtschaft, die Unterjochung durch die fremdländische, syrische Hierarchie hinzu, der patriotische Klerus schart sich daher um Sahak, dem allein der rechtmäßige Thron des Erleuchters Gregor gebührt.

${ }^{144}$ Belege bei WEBER (wie Anm. 140), 509, Anm. 2.

${ }^{145}$ So erhält nach Faustus, hist. III,5, der jungfräuliche Sohn Gregors, Aristakes, den Vorrang vor seinem verheirateten Bruder Werthanes, obwohl dieser älter war. Werthanes lebte als Priester, nicht aber als Patriarch in der Ehe. "Persische" Zustände im Klerus waren Faustus, bist. III,15, verhaßt.

${ }^{146}$ Vgl. die insgesamt zutreffenden Beobachtungen von GARSOÏAN, Epic Histories attributed to (wie Anm. 140), 53f. Wenn die Verf. behauptet "celibacy was not a requirement for ecclesiastical office in the fourth or fifth century" (ebd., 54, Anm. 251), so ist damit das Problem der Klerikerenthaltsamkeit in der armenischen Kirche nur sehr unzureichend beschrieben. Die Kontroverse zwischen Armeniern und Persern entzündet sich vielmehr an der Frage, ob die Eheschließung nach der Weihe statthaft sei. In diesem Punkte vertraten die Armenier offenkundig eine andere Sicht als die Perser nach (484) 486.

${ }^{147}$ Vgl. dazu auch WEBER (wie Anm. 140), 363f; zum beträchtlichen Vermögen der Katholikoi vgl. ebd., 367-370. Bestes Beispiel dafür, daß ein junger Mann auch gegen seinen Willen aus dynastischer Erwägung in die Ehe gedrängt wurde, ist Jussik (Faustus, bist. II,5), der nur einmal mit seiner Frau zwecks Zeugung von Nachkommenschaft lustlos schlief, dann aber den ungeteilten Christusdienst der Ehe vorzog. Vorbild waren ihm die kappadozischen Mönche und die heiligen Väter, die ihm auch die heiligen Weihen erteilten, vgl. WEBER (wie Anm. 140), 371f.

${ }^{148} \mathrm{Vgl}$. ThOMson, History of Łazar P'arpets'i (wie Anm. 127), 29f. Aus dem Brief (ebd., 254f) des späten Mönches und Kathedralpriesters von Vałarschapat Lazarus geht eindrücklich hervor, daß gewisse übelgesinnte Kreise in der Hierarchie ihm die Jugendsünden vor seiner Bekehrung zur Last legten. 
seiner Zeit ein und nimmt damit indirekt die spätere Anklage der "Paulikianer" ${ }^{149}$ vorweg.

\section{Das religiös-politische Umfeld des persischen Christentums}

Sowohl in seiner Monographie zu Barsauma als auch in einem kleineren, separat publizierten Aufsat ${ }^{150}$ bestreitet Gerö jeglichen äußeren Einfluß zoroastrischer Ethik auf die antiasketische Bewegung innerhalb der persischen Kirche. Mit dieser Anschauung setzt er sich dezidiert von älteren Untersuchungen ${ }^{151} \mathrm{ab}$. Doch gilt es gerade für den Historiker die schlichte Wahrheit zu bedenken, daß jede gute perspektivische Darstellung ihren Vordergrund und ihren Hintergrund hat und daß der Vordergrund oft nur deshalb so lebendig wirkt, weil er vom Hintergrund seine scharfen Konturen empfängt. Vordergründig betrachtet, scheint es sich beim Streit um die Klerikerenthaltsamkeit in der nestorianischen Kirche zunächst um ein innerkirchliches Phänomen zu handeln, das durch die monophysitische bzw. messalianische Propaganda auf dem persischen Territorium hervorgerufen wurde. Jedoch zeigt gerade die Synode von 497, daß man auch außerkirchlich durch den Großkönig Zamasp massiv unter Druck gesetzt war. Wenngleich sich ein abgerundetes Bild des Verhältnisses von Kirche und Staat ${ }^{152}$ weder für die Sasanidenzeit noch für die nachfolgende arabische Eroberung zeichnen läßt, so wäre es doch äußerst naiv, politische und sonstige sozio-kulturelle Einflüsse auf das persische Synodenwesen gänzlich zu leugnen ${ }^{153}$.

${ }^{149}$ Vgl. N. GARSOÏAN, The Paulician Heresy, The Hague-Paris 1967. Neben bedenklichen gnostisch-manichäistischen Quellen bezog diese Splittergruppe ihre Schlagkraft aus der Reaktion gegen das feudal-hierarchische Kirchenwesen Armeniens.

${ }^{150}$ Vgl. GERÖ, Barsauma (wie Anm. 2), 79-88, und auch DERS., Die antiasketische Bewegung im persischen Christentum - Einfluß zoroastrischer Ethik?, in: OCA 221 (1983) 187 191.

${ }^{151}$ Vgl. hierzu bes. A. VöÖBUS, Les messaliens et les réformes de Barçauma de Nisibe dans l'église perse, Pinneberg 1947.

${ }^{152}$ Vgl. dazu den Überblick bei SELB (wie Anm. 72), 161-165. 220-223.

${ }^{153}$ Eine gewisse Inkonsistenz besteht in Gerös Argumentation, wenn er zwar eingangs auf den zeitgeschichtlichen Kontext des ostsyrischen Christentums verweist, andererseits aber gesellschaftliche Einflüsse auf die Gestalt der persischen Kirche in der höchst sensiblen Frage der Klerikerenthaltsamkeit gänzlich verneint (Barsauma [wie Anm. 2], 14-24). 


\subsection{Asketische Bewegungen im Zoroastrismus?}

Die Frage, ob die zoroastrische Religion ${ }^{154}$ eine asketische Lebensweise begünstige, muß entschieden verneint werden. Während der Sasanidenherrschaft gab es zwischen Christen und Zoroastriern in mehreren religiösen Grundsatzfragen heftige Auseinandersetzungen. Die Märtyrerakten sind voll von solchen Zusammenstößen, die sich, wie noch im einzelnen zu zeigen sein wird, nicht selten an der Frage einer christlich motivierten Askese ${ }^{155}$ entzündeten. Ein zoroastrisches Pendant zur christlichen Klerikerenthaltsamkeit sucht man in den gängigen Pahlavi-Quellen vergebens, obwohl der Gedanke einer rituellen bzw. kultischen Reinheit des Priesters den alten Persern ${ }^{156}$ durchaus nicht völlig fremd war. Es ist gewiß kein Zufall, daß man in den einschlägigen persischen Lasterkatalogen ${ }^{157}$ zwar Verstöße der Priesterkaste gegen die reine Lehre, Habgier und Nachlässigkeit in rituellen Handlungen geahndet wissen will, daß aber die Keuschheitssünden keine Erwähnung finden. Christensen ${ }^{158}$ charakterisiert die zoroastrische Religion als generell antiasketisch, und auch Zaehner ${ }^{159}$ hält den Zoroastrismus für

${ }^{154}$ Basisliteratur sind die noch immer nicht überholten Standardwerke: G. WIDENGREN, Die Religionen Irans, Stuttgart 1965, mit religionsgeschichtlich wertvollen Beobachtungen zur Sasanidenzeit vgl. 243-319; R. C. ZAEHNER, Zurvan. A Zoroastrian Dilemma, Oxford 1955, (repr. New York 1972); H. S. NYBERG, Die Religionen des alten Iran, Leipzig 1938, (repr. Osnabrück 1966); A. CHRISTENSEN, Études sur le zoroastrisme de la Perse antique, Kopenhagen 1928, behandelt vorwiegend Einzelfragen. Zu berücksichtigen ist ferner der Überblicksartikel von J. DUCHESNE-GUILLEMIN über den Zoroastrismus bei E. YARSHATER, The Cambridge History of Iran 3/2. The Seleucid, Parthian and Sasanian Period, Cambridge 1983, 866-908.

${ }^{155}$ SElB (wie Anm. 72), 141, bringt es auf den Punkt, wenn er sagt: "Man lebte in einer heidnischen Umwelt, die an eine vollkommene geschlechtliche Askese nicht glaubte".

${ }^{156}$ WIDENGREN, Religionen Irans (wie Anm. 154), 264, stützt sich für seine Ausführungen auf Clem. Alex., strom. III,6,48 (PG 8,1147-55), doch sind hier offensichtlich nicht die Magier, sondern gnostische Sektierer (Karpokratianer oder Mandäer, die ihrerseits den aufkeimenden Manichäismus begünstigten?) gemeint.

${ }^{157}$ Belege bei CHRISTENSEN, L'Empire des Sassanides (wie Anm. 57), 68. Man halte nur die gängigen kirchlichen Kanones daneben, um die Unterschiede zwischen den beiden Religionsgemeinschaften festzustellen.

${ }^{158}$ Christensen resumiert: "En somme, les grands de la Perse vivaient intensivement, en partageant leur temps assez également entre l'exercice des armes à la guerre et à la chasse, et les molles voluptés. Le zarathoustrisme ennemi de tout ascétisme ne leur imposait aucun frein, mais la vie active en plein air aura neutralisé, en quelque mesure, l'effet affaiblissant des jouissances" (ebd., 108).

${ }^{159}$ ZAEHNER, Zurvan (wie Anm. 154), 176: "Of all religions Zoroastrianism was probably the most averse to ascetism, nor had it any Manichean notions about matter being evil". 
die askesefeindlichste Religion überhaupt. Ehe- und kinderlos zu sterben galt als schwer zu tilgender Makel ${ }^{160}$, für (männliche) Nachkommenschaft war in jedem Falle seitens der Hinterbliebenen zu sorgen. Ehelosigkeit um des Himmelreiches willen war im Zoroastrismus völlig undenkbar und auch von dessen eigentümlicher Eschatologie ${ }^{161}$ her nicht geboten. Im Bundahišn ${ }^{162}$, einem späten, aus der Zeit nach der arabischen Eroberung stammenden Traktat der Parsen über die Kosmographie wird für den künftigen Paradieseszustand die Praktizierung der Sexualität, wenngleich ohne Kinderzeugung, als selbstverständlich vorausgesetzt. Der in den Evangelien ${ }^{163}$ mehrfach bezeugte und für die Frömmigkeit der Alten Kirche so bedeutsame Gedanke, das engelgleiche Leben der kommenden Welt durch Enthaltsamkeit in diesem Äon zu antizipieren, wäre einem Zoroastrier absurd vorgekommen. Die persische Frömmigkeit ist weltzugewandt, es gilt die im Awesta aufgestellte Maxime: Und ich sage, o Spitama Zarathustra: Der Mann, der eine Frau hat, ist dem überlegen, der in Enthaltsamkeit lebt. Der Mann, der ein Haus hat, ist dem überlegen, der keins hat. Der Mann, der einen Sobn hat, ist dem überlegen, der keine Söhne hat. Der Mann, der Vermögen hat, ist dem überlegen, der keins hat ${ }^{164}$.

M.-L. Chaumont ${ }^{165}$ führt daher die wenigen asketischen Passagen im Pahlavi-Dênkart auf manichäistische, christliche oder gar buddhistische, keineswegs aber genuin zoroastrische Einflüsse zurück. Molé läßt lediglich einen eingeschränkten, der dynastischen Reinheit dienenden Aske-

${ }^{160}$ Belege bei CHRISTENSEN, L'Empire des Sassanides (wie Anm. 57), 50.

${ }^{161}$ Die persischen Paradiesesvorstellungen sind freilich nicht so derb-sinnlich wie die qoranischen, vgl. zum syr. Hintergrund der "Paradiesesjungfrauen" E. BECK, Eine christliche Parallele zu den Paradiesesjungfrauen des Korans, in: OCP 14 (1948) 398-405; frz. Zusammenfassung in DERS., Les Houris du Coran et Éphrem le Syrien, in: Mélanges de l'Institut dominicain d'Études orientales du Caire 6 (1961) 405-408. Vgl. dazu auch Chr. LuXENBERG, Die syro-aramäische Lesart des Koran, Berlin 2004, 254-294.

${ }^{162}$ Vgl. F. JuSTI, Der Bundehesh, Leipzig 1868, (repr. Hildesheim 1976), 43: Jedem wird man das Weib geben und ibm die mit dem Weib (einst erzeugten) Kinder zeigen; sie werden so thun, wie jetzt in der Welt, aber Erzeugung von Kindern wird nicht mebr sein.

${ }^{163}$ Vgl. Mt 22,29-32; Mk 12,24-27; Lk 20,34-38. Zur Deutung vgl. auch P. NAGEL, Die Motivierung der Askese in der Alten Kirche und der Ursprung des Mönchtums, Berlin 1966, 34-55. Nagel verweist auf interessante Lesarten der altsyrischen Evangelienüberlieferung, die einer asketischen Interpretation des Herrenwortes sehr förderlich waren (ebd., 36, Anm. 3).

164 Übers. nach M. L. CHAUMONT, Vestiges d'un courant ascétique dans le Zoroastrisme sassanide d'après le VI' live de Dênkart, in: RHR 156 (1959) 1-24, hier: 7.

${ }^{165}$ Vgl. ebd., 23. 
tismus $^{166} \mathrm{zu}$, während sich Zaehner ${ }^{167}$ in seiner Beurteilung der zervanitischen Askese am weitesten vorgewagt hat. Zwar wisse der Zervanit - so die These - um die zerstörerische Kraft des Dämons Âz, welcher die böse Begierde in der Eß- und Trinklust, im Sexualtrieb und in der Habsucht des Menschen repräsentiere, doch fänden wir im ursprünglichen Zervanismus ${ }^{168}$ kein Indiz für die klerikale Enthaltsamkeit, im Gegenteil, die Zugehörigkeit zur künftigen Paradiesesherrlichkeit werde ganz allgemein von der Zeugung edler Nachkommenschaft ${ }^{169}$ abhängig gemacht.

Auf diesem zeitgenössischen religiösen Hintergrund ${ }^{170}$ läßt sich die im Kern als authentisch anzusehende christlich-zoroastrische Debatte nachvollziehen, die uns die Chronik von Seert für die Zeit Bahrâms II. (276-293) überliefert: $\operatorname{Er}$ (der Großkönig) fand heraus, daß die Manichäer sich als Christen ausgaben, sich binter ibren Moden versteckten, Ebe und Kinderzeugung wie die Katholikoi und Bischöfe verwarfen. Er bielt die beiden Sekten für verdorben, da ibre Verkebrtheiten übereinstimmten, und gab den Befehl, die Manichäer zu töten und ibre Gebetsstätten zu zerstören. Die Magier verfolgten daraufbin unterschiedslos die Christen... Da beklagten sich die Christen bei König Babrâm über das, was ibnen widerfahren war. Daraufhin wollte dieser den Unterschied zwischen ibnen und den Manichäern wissen. Und er fragte sie, aus welchem Grunde den Katholikoi und Bischöfen die

${ }^{166}$ Vgl. M. MOLÉ, Un ascétisme moral dans les livres pehlevis?, in: RHR 155 (1959) 145 190, hier 190: “Certes, la morale pratique est à l'opposé de l'ascétisme. On aurait tort cependant de négliger certaines nuances qui sont capitales. Les relations sexuelles ne sont pas recommandées en tant que telles, mais dans la mesure où elles servent à la procréation dans la famille légitime où la pureté de la lignée est préservée".

${ }^{167}$ Vgl. ZAEHNER, Zurvan (wie Anm. 154), 176-182. Er charakterisiert die unterschiedlichen Typen der Askese wie folgt: "The Christian schools his body in subjection to his soul to open wide the doors of grace: the Manichee fasts and abstains from sexual intercourse in order to release the particles of light that are imprisoned in matter. The Zervanite, however, would fast, practice chastity, and 'give up the world' in order to eliminate concupiscence, the basic evil, as far as possible from his own person” (ebd., 132).

${ }^{168}$ Es hat im Zervanismus wohl nur eine Partialaskese gegeben, die darauf zielte, den Dämon des "Exzesses und des Mangels", Âz, zu überwinden und das rechte Maß der Vernunft (patmân) wiederherzustellen, vgl. dazu ZAEHNER, Zurvan (wie Anm. 154), 166-183.

${ }^{169}$ Vgl. Pahlavi Rivâyat 36,12f: Er (Zarathustra) sprach zu Abura Mazdâ: "Sterblich zu sein erscheint mir besser, als dauerhaft obne Nachkommen zu leben". Abura Mazdâ sprach: "Recht so, du bast gut verstanden, Zarathustra. Wer edlen Nachwuchs hat, erscheint mir besser als derjenige, der dauerhaft obne Nachkommen lebt. Denn nicht wird ins Paradies (vahišt) eingeben, wer durch eigenes Vergeben (pat vinâskarîh) keine Frau bat". Übers. nach MOLÉ (wie Anm. 166), 153.

${ }^{170}$ Vgl. GeRÖ, Barsauma (wie Anm. 2), 87. 
Heirat und Zeugung von Nachkommenschaft in der Welt untersagt seien. Er sagte, wenn dies bei ibnen böse und verboten sei, dann seien sie des Todes, da ibre Absicht die Vernichtung der Welt sei, wenn es aber statthaft und schön sei, warum enthielten sich dann ibre Fübrer dieser Dinge und verachteten sie? Daraufhin antworteten die Christen, daß die Manichäer an zwei Götter glaubten... Sie (die Christen) erachten die Ehe für gut und schön, zumal da sie dazu in ibren Schriften angebalten werden, jedoch entbielten sich dieser Dinge ibre Fübrer, um nicht in der Ausübung der Hirtensorge, zu der sie bestellt sind, gebindert zu sein, d. b. in der Beständigkeit des Gebets und der Fürsprache für die Welt und ibre Bewobner, für den König und das Reich ${ }^{171}$.

Angesichts des mesopotamischen Ursprungs des Manichäismus ${ }^{172}$ verwundert es wenig, daß die Klerikerenthaltsamkeit bei den Zoroastriern pauschal unter Verdacht geriet. Syrische Kirchenväter wie Ephräm ${ }^{173}$ hatten alle Hände voll zu tun, die christliche Lehre gegen den dualistischen Rivalen abzugrenzen. Das dritte Siegel Manis sieht nämlich in Analogie zum Buddhismus für die electi die vollkommene geschlechtliche Enthaltsamkeit und den Verzicht auf jegliche leibliche Nachkommenschaft ${ }^{174}$ vor, um die eingeschlossenen Lichtpartikel von der verhaßten Materie zu lösen. Doch kann innerhalb des christlichen Schöpfungsglaubens von einer solchen pessimistischen Welt- und Menschensicht keine Rede sein. Begründet wird die klerikale Enthaltsamkeit vielmehr mit der ungeteilten Hingabe an den Hirtendienst und der rückhaltlosen Verfügbarkeit für das beständige Gebet (arab. mulâzamat aṣ-șalât), zu dem die "höheren Kleriker", Bischöfe und Katholikoi $^{175}$, unbedingt verpflichtet sind. Von den "niederen Klerikern" wie Priestern und Diakonen ist bezeichnenderweise nicht die Rede. Die Enthaltsamkeitsdisziplin ist nach Auskunft der Chronik sehr alt und reicht offensichtlich weit in die vormanichäische Zeit zurück, kann also nicht auf außeroder gar antichristliche Einflüsse zurückgeführt werden. Im Gegenteil, nach

\footnotetext{
${ }^{171}$ Chronik von Seert IX (PO IV 237f).

172 Vgl. dazu Widengren, Religionen Irans (wie Anm.154), 299-308; DerS., Manichaeism and its Iranian background, in: E. YARSHATER, The Cambridge History of Iran 3/2. The Seleucid, Parthian and Sasanian Period, Cambridge 1983, 965-990.

${ }^{173}$ Vgl. E. BECK, Des hl. Ephräm des Syrers Hymnen contra haereses, Louvain 1957 (= CSCO 169f).

${ }^{174}$ Vgl. Widengren, Manichaeism (wie Anm. 172), 985.

${ }^{175}$ Der Terminus stellt in diesem frühen Kontext einen Anachronismus dar. Gemeint ist der "Erzbischof" von Seleukia-Ktesiphon, der die Sache der Christen vor dem Großkönig
} vertritt. 
Darstellung des Chronisten sind es ja die Häretiker, welche die Gebräuche der Christen kopieren und korrumpieren, also auch die Idee der Askese pervertieren. Die christliche Begründung für die klerikale Enthaltsamkeit wird schließlich vom Großkönig nicht zuletzt deshalb akzeptiert, weil sich der persische Christ grundsätzlich loyal auch gegenüber einer heidnischen Obrigkeit verhält und sie in das fürbittende Gebet der Kirche einschließt. Gleichwohl bleibt die Askese als solche, und insbesondere die der Kleriker, den Persern fremd. Insofern haben monophysitische Chroniken trotz ihrer tendenziösen Darstellungsweise nicht unrecht, wenn sie in der Aufhebung der Klerikerenthaltsamkeit eine Konzession an den Geschmack des Großkönigs $^{176}$ sehen wollen. Dies gilt im besonderen Maße für Qawad ${ }^{177}$ und seine mazdakitischen Umtriebe, die man durchaus als die große "sexuelle Revolution" der persischen Gesellschaft bezeichnen könnte. Der Konflikt mit der christlichen Verkündigung war daher vorprogrammiert und entlud sich nicht selten in Form von brutaler Verfolgung und blutigem Martyrium.

\subsection{Das Ideal der persischen Märtyrerkirche}

Zwar finden wir in den Anfängen des syrisch-persischen Christentums bei Aphrahat $(\dagger \text { nach } 345)^{178}$ keinen expliziten Hinweis auf die klerikale Enthaltsamkeit, doch ist eine solche auf dem Hintergrund der stark asketisch geprägten Frömmigkeit mit guten Gründen zu vermuten. Eine Geschichte der frühsyrischen Askese ${ }^{179}$ kann hier nicht geboten werden, sie war keineswegs nur auf Kleriker beschränkt, sondern umfaßte auch derart den Laienstand, daß in der Forschung gelegentlich die aberwitzige These vertreten

${ }^{176} \mathrm{Vgl}$. dazu GERÖ, Die antiasketische Bewegung (wie Anm. 150), $189 \mathrm{f}$.

${ }^{177}$ Nach dem Zeugnis der Chronik von Seert (PO VII/2,125) habe Qawad die ohnehin laxe Ehemoral der Perser durch den Bau von Bordellen zur Förderung der allgemeinen Lust zusätzlich untergraben, was in gewissem Kontrast zur ansonsten recht spartanischen Hofhaltung des Großkönigs (er war kein Gourmet, entließ daher seine Köche und vermied jeglichen Tafelaufwand) steht. Es entsprach aber durchaus der "sozialistischen" Moral der Mazdakiten, daß nicht nur Privatvermögen brutal enteignet wurde, sondern auch die Frauen zu bestimmten "Gemeinschaftsdiensten" herangezogen wurden. Immerhin war es ein Zeichen von "Emanzipation", daß sich die Frauen im Gegenzug mehrere Männer halten durften. Leidtragende der zerrütteten Familienverhältnisse waren jedoch immer, wie Tabari betont, die Kinder, die aus jenen Verbindungen hervorgingen, vgl. NÖLDEKE (wie Anm. 33), 141f.

${ }^{178}$ J. PARISOT (ed./tr.), Aphraatis Sapientis Persae Demonstrationes I-XXII (= PS I), Demonstratio XXIII (= PS II,1-489), Lutetiae Parisiorum 1894/1907, dt. bei P. BRUNS, Aphrahat. Unterweisungen I-II, Freiburg 1991.

${ }^{179}$ Hier sei nur auf die monumentale Untersuchung bei A. VÖÖBUS, History of Ascetism in the Syrian Orient, Louvain 1958 (= CSCO 184), verwiesen. 
werden konnte, nur Asketen hätten zur Gemeinde des Aphrahat ${ }^{180}$ gehört. Theologische Sinnmitte jeglicher Form der christlichen Weltentsagung bildet nach Aphrahat, dem. VI,8f, die Gleichförmigkeit mit Christus. In der Nachfolge des Herrn verschmilzt der Jünger zu innerster Wesenseinheit mit seinem Meister. Terminologisch wird diese Identität durch die Verwendung des Begriffes ihidâyâa, der sowohl dem "Eingeborenen" (Joh 1,14) als auch der "monastischen" Existenz beigelegt wird, zum Ausdruck gebracht. Die sexuelle Enthaltsamkeit wird bei Aphrahat aber nicht nur christologisch mit dem Beispiel Christi, sondern auch protologisch mit der jenseits sexueller Bipolarität lebenden Adamsgestalt (dem. XVIII,9) vor dem Sündenfall begründet oder aber als Antizipation des endzeitlichen Paradieses (dem. XXII, 12f) verstanden. Ehelosigkeit ist das Kennzeichen einer ungeteilten Hingabe an Gott, den Vater, und den Heiligen Geist, die Mutter (dem. XVIII,10). Ein grundsätzlicher Sinnunterschied zum asketischen Rigorismus Markions, der valentinianischen Gnosis und des Manichäismus sieht Aphrahat darin, daß die christliche Askese den Leib für die Auferstehung des Fleisches rein bewahrt und für ihre Enthaltsamkeit Lohn erwarten kann (dem. III,9).

Aufs Ganze gesehen, unterscheidet Aphrahat drei Typen von Christen: die Elite der nach den evangelischen Räten lebenden Mönche und Jungfrauen (dem. VII,19-22), sodann diejenigen Eheleute, welche die Ehe nicht mehr vollziehen und im Stande der Enthaltsamkeit (qaddišûtâ) verharren (dem. VI,4), und schließlich das Gros der Verheirateten. Die Ehe war vor und nach der Taufe freigestellt; der einmal gefaßte Entschluß zur Ehelosigkeit war jedoch endgültig (dem. VI,4; VII,18). Das christliche Ideal blieb für den frühen Syrer die Ehelosigkeit, die Ehe galt grundsätzlich, da sie an diese vergängliche Weltzeit gebunden ist, als weniger verdienstvoll (dem. XVIII,8). Es bedarf keiner weiteren Erläuterung, daß in einem solchen religiösen Kontext nicht der Zölibat, sondern die Priesterehe ein ernstes Problem darstellt.

Der Schwerpunkt des persischen Christentums lag zur Zeit Aphrahats in der Mitte des vierten Jahrhunderts im nördlichen Zweistromland und in der östlich des Tigris gelegenen Adiabene, d. h. also von den Residenzstädten des Großkönigs her betrachtet, an der westlichen Peripherie des Reiches. Doch läßt bereits dem. XIV den wachsenden Einfluß der Hauptstadt Seleukia-Ktesiphon auf die einzelnen Lokalkirchen erkennen. Die Synoden von 410, 424 und 486 dokumentieren diese Entwicklung auch auf der kano-

${ }^{180} \mathrm{Vgl}$. A. VÖÖBUS, Celibacy. A Requirement for Admission to Baptism in the Early Syrian Church, Stockholm 1951. 
nistischen Ebene, indem sie die Privilegien des Bischofsstuhls von SeleukiaKtesiphon bestätigen. Im fünften und sechsten Jahrhundert mehren sich jene Kanones ${ }^{181}$, welche die Verwandtenehe untersagen, ein deutliches Indiz für den Umstand, daß die christliche Mission weit ins persische Kernland vorgedrungen war. Die zahlreichen persischen Namen in den Märtyrerakten ${ }^{182}$, darunter nicht wenige von Notabeln und einflußreichen Hofbeamten, lassen erkennen, wie sehr sich das Christentum bereits im fünften Jahrhundert von seinen provinziellen Eigenarten gelöst hatte und zu einer ernstzunehmenden politischen Größe im Zentrum des Sasanidenreiches geworden war. Der neue Glaube war selbst unter eingefleischten Aristokraten salonfähig geworden, während der traditionelle Zoroastrismus in höheren Kreisen an Einfluß verlor, wenngleich er noch immer die prägende religiöse Kraft der persischen Gesellschaft blieb. Leute wie Barsauma und Aqâq hatten die Gunst der Stunde erkannt und glaubten, die "Inkulturation" in das weltoffene persische Milieu durch die Preisgabe alter asketischer Traditionen fördern zu müssen. Gegen diese z. T. recht fragwürdige Anpassungsversuche an Mentalität und Zeitgeist stand ein unbeugsames Bekennertum, das die alten asketischen Ideale hochhielt und sich nicht selten in schroffer Abgrenzung zu den offenkundigen Verweltlichungstendenzen in der Kirche definierte.

Die syro-persischen Märtyrerakten stecken voller Polemik gegen das zeitgenössische Zoroastriertum und stellen eine unersetzliche Quelle für die iranische Religionsgeschichte dar, deren Wert freilich nicht immer erkannt wurde. Neben dem Gottesbild, den Reinheitsgeboten und der Loyalität gegenüber dem persischen König war auch die klerikale Enthaltsamkeit Gegenstand heftiger religiöser Kontroversen ${ }^{183}$. Noch in die Zeit Schapurs II.

${ }^{181} \mathrm{Vgl}$. SELB (wie Anm. 72), $152 \mathrm{f}$.

${ }^{182}$ Die Märtyrerakten liegen in mehreren Rezensionen vor: S. E. AsSEMANI, Acta sanctorum martyrum orientalium et occidentalium I, Romae 1748; P. BEDJAN, Acta martyrum et sanctorum II.IV, Lutetiae Parisiorum 1891.1894 (syr.), auf armenisch in der von Mechitaristen besorgten zweibändigen Ausgabe, Venedig 1874, und griechisch bei H. DELEHAYE, Les versions grecques des actes des martyrs persans (= PO II,403-560); dt. Auswahl bei O. BRAUN, Ausgewählte Akten persischer Märtyrer (= BKV 22 ), Kempten 1915; ältere Übersetzung bei G. HOFFMANN, Auszüge aus syrischen Akten persischer Märtyrer, Leipzig 1880, (repr. 1966 Nendeln/Liechtenstein). Grundlegende historisch-theologische Untersuchung bei G. WIESSNER, Zur Märtyrerüberlieferung aus der Christenverfolgung Schapurs II., Göttingen 1967.

${ }^{183}$ Eine Zusammenfassung der zoroastrischen Vorwürfe gegen die christliche Religion liegt im Martyrium des Bischofs Akebschemâ, zit. nach BRAUN, Ausgewählte Akten (wie Anm. 182), 116, vor: Die Christen zerstören unsere Lebre und lebren die Menschen, einem Gott allein zu dienen, die Sonne nicht anzubeten, das Feuer nicht zu ebren, das Wasser durch 
(309-379) fällt das Martyrium des unverheirateten Diakons Aitillâhâ (Zeichen Gottes) aus der Adiabene, der beim Verhör aufgefordert wird: Bete die Sonne an, trink Blut, nimm ein Weib, vollbringe den Befebl des Königs und du entrinnst der Folter und dem dir bestimmten Tode ${ }^{184}$. Die Bundessöhne und -töchter bildeten die Speerspitze der christlichen Mission ${ }^{185}$ und waren daher bei den heidnischen Priestern, den Môpêts, besonders verhaßt. Wie im Falle der Marta, einer Tochter des Pusai ${ }^{186}$, hätten sich die Angeklagten durch Heirat Folter und qualvolle Hinrichtung ersparen können, doch blieben die Asketen ${ }^{187}$ zumeist standhaft. Massenhinrichtungen ${ }^{188}$ wie die des Bischofs Schâhdôst und seiner 128 Gefährten waren unter Schapur II. keine Seltenheit, der Blutzoll der Asketen und Kleriker war daher insgesamt sehr beträchtlich. Schâhdôst war der Überlieferung zufolge der unmittelbare Nachfolger des Simon auf dem Patriarchenstuhl von Seleukia-Ktesiphon. Wie sein Vorgänger lebte auch er streng enthaltsam; die Abtötung des Fleisches ${ }^{189}$ diente ihm zur Vorbereitung auf das heißersehnte Martyrium. In seinem ganz von Christusliebe ${ }^{190}$ erfüllten Herzen war kein Platz mehr für irdisches Begehren. Das Martyrium des Hofeunuchen Guschtâzâd, welches

bäßliche Waschung zu verunreinigen, nicht zu beiraten, Söbne und Töchter nicht zu zeugen, mit den Königen nicht in den Krieg zu zieben, nicht zu töten, obne Gewissensbisse die Tiere zu schlachten und zu essen, die Toten in der Erde zu begraben... .

${ }^{184}$ Ebd., 121; vgl. WIESSNER, Märtyrerüberlieferung (wie Anm. 182), 27-33.

${ }^{185}$ Einen Abriß des ostsyrischen Mönchtums nebst Regeln bietet BRAUN, Ausgewählte Akten (wie Anm. 182), 281-331.

${ }^{186}$ Vgl. ebd., 76, Anm. 1, über die tiefe Abneigung der Perser gegen die christliche Ehelosigkeit, die als Brautschaft mit Christus gedeutet wird (78f). Zur Überlieferung des Martyriums vgl. WIESSNER, Märtyrerüberlieferung (wie Anm. 182), 94-105.

${ }^{187}$ So jedenfalls die Märtyrerin Tarbo und ihre Gefährtinnen, vgl. BRAUN, Ausgewählte Akten (wie Anm. 182), 90f. Auch hier wiederum die stereotype Aufforderung des verhörführenden Môpêt, gegen die Keuschheit zu sündigen: Ich will den König bitten und euch drei vom Tode erretten; aber werde mein Weib. Zum Tarbo-Martyium vgl. WIESSNER, Märtyrerüberlieferung (wie Anm. 182), 144-148.

${ }^{188}$ Vgl. dazu ebd., 105-128; BrAun, Ausgewählte Akten (wie Anm. 182), 93-96; syr. Text bei BEDJAN, AMS II (wie Anm. 182), 276-281.

${ }^{189}$ Vgl. ebd., 277, Z. 13-17: Wie begebrt ist die Ankunft des Todes für den, der geistig existiert; aber wie furchtbar und schrecklich ist seine Kunde für den, der fleischlich wandelt... Diejenigen, die Gott liebten, gingen zu Gott; diejenigen, welche die Welt liebten, verblieben in der Welt.

${ }^{190}$ Vgl. ebd. 278, Z. 2-6: Da wurde der siegreiche Schâbdôst verhaftet, dessen Name mit "Königsfreund" übersetzt wird. Den himmlischen König liebte und begebrte er nämlich wirklich mit seiner ganzen Seele und seiner ganzen Kraft. Keusch und rein war er, wabrbaftig und beilig, so glich er dem beldenmütigen, seligen Simon. 
noch dem Simon-Kreis ${ }^{191}$ zuzuordnen ist, läßt in der jetzigen Fassung die hohe Wertschätzung, die der Endredaktor der christlichen Ehelosigkeit ${ }^{192}$ entgegenbringt, erkennen. Diese asketenfreundliche Tendenz setzt sich in der Vita des Mar $\mathrm{Aba}^{193}$ und im Martyrium des persischen Konvertiten Mar Gîwargîs (Georg) ${ }^{194}$ bis ins sechste Jahrhundert ungebrochen fort.

\section{Ausblick}

Die antiasketische Gesetzgebung des rebellischen Barsauma sowie der Katholikoi Aqâq und Babai wollte das Mönchtum und den zölibatären Klerus aus den Städten in die entlegenen Regionen verbannen. Nicht nur geographische Distanz war das Ziel, sondern die generelle Marginalisierung einer Bewegung, die das geistliche Leben der persischen Christenheit seit den Tagen Aphrahats des Persischen Weisen entscheidend geprägt hatte. Seit sich die ostsyrische Kirche in das weltoffene Milieu des Sasanidenreiches inkulturiert hatte und tatsächlich zu einer "persischen" Kirche geworden war, suchte sie ihre Abgrenzung vom Westen nicht nur auf dem Gebiet des Dogmas im Sinne einer sog. "Nestorianisierung”, sondern vielmehr im Bereich der Disziplin. Viele Asketen, Priester wie Laien, waren an den Rand der Kirche gedrängt worden, wurden als vermeintliche Häretiker gemieden oder ließen sich bereitwillig vom aufstrebenden Monophysitismus bzw. Messalianismus absorbieren. Der überwiegende Teil blieb jedoch trotz dogmatischer und disziplinärer Neuerungen der überkommenen Tradition treu, was erhebliche Unruhe in die Reihen der Gläubigen trug. Selbst Bischöfe wurden durch die Neuordnung in schwere Gewissenskonflikte gestürzt. Als der Metropolit von Arbela Mar Joseph (498-510) resignierte und sich als schlichter Mönch in die Berge zurückziehen wollte, hat ihn der verheiratete Katholikos Schîlâ (gräzisiert "Silas"; 505-521/22) in einem Mahnschreiben ${ }^{195}$ zur Diözese zurückbefohlen mit der Begründung, daß ein sol-

${ }^{191}$ Vgl. WIESSNER, Märtyrerüberlieferung (wie Anm. 182), 130; der Text ist mit der narratio Simeonis verknüpft, vgl. PS II,864-896.

${ }^{192}$ Körperlich unfruchtbar, hat Guschtâzâd doch durch sein Lebensopfer reiche geistige Frucht gebracht und ist für viele zu einem geistlichen Vater geworden, vgl. PS II,879-884. Zur Stellung der Eunuchen am persischen Hof vgl. auch BRAUN, Ausgewählte Akten (wie Anm. 182), 179.

${ }^{193}$ Vgl. ebd., 188-190.

${ }^{194}$ Vgl. ebd., 221. 226. 235f. 241.

${ }^{195} \mathrm{Vgl}$. die dt. Übers. bei KAWERAU (wie Anm. 13), 102-104. Die Zeiten sollten sich für die Asketen wiederum zum Besseren ändern. Als Isaak von Ninive, durch Katholikos Georg I. 
ches Tun als Zeichen von Messalianismus gedeutet werden könnte. Mar Joseph unterwarf sich, wie der Chronist betont, demutsvoll der Autorität des Katholikos; doch wie prekär die Lage wirklich war und wie schwach die Macht der regierenden Katholikoi, zeigt der Fortgang der Geschichte. Die Adiabene mit ihrem Zentrum Arbela erkannte unter ihrem Metropoliten Henana ${ }^{196}$ die nachfolgenden Katholikoi, Narsai und seinen Gegenspieler Elischa (524-536), nicht mehr an und ging in der Christologie eigene Wege. Mit Mar Aba I. (540-552) ${ }^{197} \mathrm{kam}$ wiederum ein heiligmäßiger Asket auf die Kathedra von Seleukia-Ktesiphon. 571 gelang es dem Mönchsvater Abraham von Kaschkar ${ }^{198}$, durch ein Musterkloster auf dem Berg Izla nach dem Vorbild der ägyptischen Sketis das nestorianische Mönchtum grundlegend zu reformieren, was nicht ohne Folgen für die klerikale, speziell bischöfliche Enthaltsamkeit blieb. Nun strahlte das Mönchtum wie ehedem weit in die persische Kirche hinein und bildete einen Gegenpol zur stark verweltlichten Hierarchie, die freilich nicht reformunwillig, sich den neuen geistigen Strömungen öffnete. So hob bereits die Synode des Katholikos Joseph I. vom Jahre $554^{199}$ die diskriminierenden Bestimmungen von 486 wieder auf und ermunterte die Mönche zum Bau von Klöstern inmitten der Städte. Eine weitere Synode von 576 bestätigte die kirchliche Wiedereingliederung des Mönchtums, und unter dem vergleichsweise kurzen Pontifikat Sabrischos I. (596-604) ${ }^{200}$ erstrahlte es zu neuer Blüte. Sabrischo war es denn auch, der die klerikale Enthaltsamkeit zumindest für die höheren Kleriker wieder verbindlich zu machen suchte. Doch scheiterte sein neuer

(658-680) zum Bischof geweiht, nach nur fünf Monaten auf sein Bistum Ninive verzichtete, um sich ganz der Beschauung zu widmen, erhob sich kein Sturm der Entrüstung.

${ }^{196}$ Vgl. ebd., 105-108. Der Metropolit Henana ist zwar nicht zu verwechseln mit dem gleichnamigen Theologen, der gegen Ende des sechsten Jahrhunderts in Nisibis wirkte und von Babai dem Großen heftig bekämpft wurde, doch blieb diese Region immer anfällig für monophysitische Ideen.

${ }^{197}$ Vgl. die leider unvollständige dt. Übers. der Vita bei BrAun, Ausgewählte Akten (wie Anm. 182), 180-220.

${ }^{198}$ Vgl. dazu TAMCKE (wie Anm. 83), 24-26.

${ }^{199}$ Vgl. dazu SELB (wie Anm. 72), 154f. Das kirchliche Vermögen wurde treuhänderisch verwaltet. Kleriker erwarben Güter für Kirchen, Klöster und Xenodochien, ließen aber den Erwerb auf ihren eigenen Namen lauten. Um die wahre Trägerschaft zu verschleiern, wurde sogar im Namen von Kindern erworben. Wegen der Aufhebung des Zölibats kam es im sechsten Jahrhundert zu größeren Schwierigkeiten mit den Erben. Kanon 11 der Synode Josephs I. (554) sah daher vor, daß Kleriker ihr Testament, anderenfalls es unwirksam sein sollte, von der Gemeinde bestätigen ließen. Verheiratete Kleriker standen in größerer Gefahr als zölibatäre, Kirchengut an ihre Nachkommenschaft zu verschleudern.

${ }^{200}$ Vgl. dazu TAMCKE (wie Anm. 83), 41-57. 
kirchenpolitischer Kurs mit seinem Tod im Jahre $604^{201}$ kläglich. Der von ihm zu seinem Nachfolger erkorene Mönch Barhadbeschabba wurde von Staat und Kirche geflissentlich übersehen. Statt dessen kam Bischof Gregor I. (605-609), ein ambitionierter Lebemann und Günstling des persischen Großkönigs, bei der Patriarchenwahl zum Zuge. Seine korrupte und auf finanziellen Profit ausgerichtete Amtsführung stürzte die persische Kirche in eine solch tiefe Krise, daß der Großkönig den Stuhl von SeleukiaKtesiphon lange vakant ließ. Daher führte der Mönch und Mystiker Babai die Kirche im zusammenbrechenden Sasanidenreich aus dem Untergrund; seine Wahl zum Katholikos-Patriarchen im Jahre 628 lehnte er allerdings wohlweislich ab.

Im exegetischen Sammelwerk Buch der Biene nennt Salomon von Basra (um 1222) in Kap. $50 \mathrm{f}^{202}$ die Namen verheirateter Apostel, darunter merkwürdigerweise auch Paulus, und fügt bei den Patriarchen des fünften Jahrhunderts hinzu, daß lediglich Babai und Silas verheiratet gewesen seien. Von den anderen ist ihm derartiges nicht bekannt, ein Großteil wird bei ihm vielmehr explizit unter die Mönche gerechnet. Der englische Entdeckungsreisende George Percy Badger ${ }^{203}$, der uns eine detaillierte Beschreibung des nestorianischen Geisteslebens im 19. Jahrhundert hinterlassen hat, konstatiert, daß die alten Kanones des Synodicon Orientale zu seiner Zeit längst außer Kraft seien. Die Zweitehe für Kleriker sei strikt verboten, der höhere Klerus lebe ehelos, eine Praxis, die durch die unierten Chaldäer unter Leitung von französischen Lazaristen und Dominikanern noch gefördert worden sei.

So blieb Barsauma auch in der eigenen ostsyrischen Kirchengeschichte nur eine kurze, aber durchaus spannungsgeladene Episode.

${ }^{201}$ Vgl. dazu ebd., 59f. Der Mönchsbischof Sabrischo blieb ein gestrenger Verteidiger des Ehebandes und scheute nicht den Konflikt mit dem persischen Großkönig, der sich von seinem mit dem Bann belegten bigamistischen Hofarzt nicht trennen wollte.

${ }^{202}$ Vgl. SCHÖNFELDER (wie Anm. 109), 83-85. Zur Zeit des Rabban Sauma und Jahballahas III., des ersten Mongolen auf der Kathedra, lebten die Katholikoi und die Bischöfe enthaltsam, vgl. die engl. Übers. bei E. A. W. BuDGE, The Monks of Kublai Khan, Emperor of China, 1928. Doch galt diese Bestimmung nur für die höheren Kleriker, nicht für die niederen, wie Wilhelm von Rubruk bezeugt.

${ }^{203}$ G. P. BADGER, The Nestorians and their rituals I-II, London 1852 (repr. London 1987), hier: II, 178-181. 